\title{
Offshoring and Jobs: The Myriad Channels of Influence*
}

\author{
Jose L. Groizard \\ Departament d'Economia Aplicada \\ Universitat de les Illes Balears
}

\author{
Priya Ranjan ${ }^{\dagger}$ \\ Department of Economics \\ University of California, Irvine
}

\author{
Antonio Rodriguez-Lopez \\ Department of Economics \\ University of California, Irvine
}

Final version: September 2014

\begin{abstract}
Offshoring reallocates jobs inside firms, between firms, and across sectors, affecting the economy-wide unemployment rate. We study these channels in a model with labor market frictions and two sectors - a differentiated-good sector comprising heterogeneous firms that can offshore, and a homogeneous-good sector. A decline in offshoring costs affects intrafirm and intrasectoral reallocation of jobs in the differentiated-good sector through a selection effect, a productivity effect, and a job-relocation effect. The key parameters determining the impact of offshoring on jobs at various margins, as well as on the economy-wide unemployment rate, are the elasticity of substitution between inputs, the elasticity of substitution between varieties of differentiated goods, and the elasticity of demand for differentiated goods as a whole. Changes in search frictions affect unemployment both directly and through their interaction with offshoring.
\end{abstract}

JEL Classification: F12, F16

Keywords: heterogeneous firms, offshoring costs, search frictions, unemployment

\footnotetext{
${ }^{*}$ We thank Theo Eicher (the editor) and two anonymous referees for extremely helpful comments and constructive suggestions. All errors are our responsibility. E-mail addresses: Groizard (joseluis.groizard@uib.es); Ranjan (pranjan@uci.edu); Rodriguez-Lopez (jantonio@uci.edu).

${ }^{\dagger}$ Corresponding author. Department of Economics, University of California, Irvine. Address: 3151 Social Science Plaza, Irvine, CA 92697-5100, USA. Telephone number: +1 (949) 824-1926. Fax number: +1 (949) 824-2182.
} 


\section{Introduction}

Offshoring refers to the relocation abroad of a part of a firm's production process either within the firm's boundary or through arm's length trade. Since the relocation of the production process goes hand in hand with the relocation of jobs, it gives rise to the fear - fed by media stories - that there are job losses in the country whose firms engage in offshoring. ${ }^{1}$ Not only has this caused anxiety among the public at large, but politicians in the U.S. (on both sides of the aisle) and Europe have done fear-mongering regarding offshoring. ${ }^{2}$ This has also given rise to calls to throw sand in the wheels of offshoring to stem job losses. However, this story ignores the various channels through which offshoring affects jobs. Before implicating offshoring as the main source of job losses, we need to understand its overall employment effects and not just the immediate job-relocation effect. This paper constructs a two-sector theoretical model with labor market frictions to identify the channels through which offshoring affects jobs (at the firm and industry levels) and the economywide unemployment rate.

Our model includes a homogeneous-good sector (which uses only domestic labor) and a differentiated good sector (which can use both domestic and foreign labor). Firms in the differentiated-good sector are heterogeneous in productivity and use a continuum of intermediate inputs to assemble final goods. The production of each intermediate input can be either offshored or undertaken using domestic labor, but offshoring is subject to fixed and variable costs. In addition, there are search frictions in both sectors affecting the hiring of domestic workers. Workers are mobile across sectors but because of differences in search parameters, unemployment rates and wages differ across sectors. The economy-wide unemployment rate depends on both the sectoral unemployment rates as well as on the share of workers in each sector.

We show that a reduction in the variable cost of offshoring affects intrafirm and intrasectoral employment in the differentiated-good sector through three channels. Following a reduction in the offshoring cost, offshoring firms increase the fraction of inputs they offshore, which reduces their domestic employment. This is the job-relocation effect of offshoring. As well, offshoring firms become more productive as a result of lower input costs, which allows them to charge lower prices. If the elasticity of substitution between inputs is smaller than the elasticity of substitution

\footnotetext{
${ }^{1}$ For example, The Economist (Jan 19th, 2013) says: "But offshoring from West to East has also contributed to job losses in rich countries, especially for the less skilled, yet increasingly for the middle classes too... In a survey by NBC News and the Wall Street Journal in 2010, $86 \%$ of Americans polled said that offshoring of jobs by local firms to low-wage locations was a leading cause of their country's economic problems."

${ }^{2}$ The same article in The Economist above notes: "Barack Obama's presidential campaign last year repeatedly claimed that his rival, Mitt Romney, had sent thousands of jobs overseas when he was working in private equity. Mr Romney, in turn, attacked Chrysler, a car firm, for planning to make Jeeps in China. France's new Socialist government has appointed a minister, Arnaud Montebourg, to resist 'delocalisation'. Germany's chancellor, Angela Merkel, worries publicly about whether the country will still make cars in 20 years' time."
} 
between differentiated-good varieties, the resultant increase in demand for offshoring firms' products translates into higher domestic employment. We call this the productivity effect of offshoring on employment. Lastly, as market shares are reallocated from non-offshoring to offshoring firms, the residual demands and gross profits of non-offshoring firms decline; this causes the death of the least productive non-offshoring firms (who are no longer able to cover the fixed costs of production) and a contraction in employment of the rest of them. We refer to this channel as the selection effect of offshoring.

A reduction in offshoring costs affects the number of firms as well. In addition to the lowproductivity non-offshoring firms that die, the number of entrants may increase or decrease depending on the elasticity of demand for differentiated goods. As the aggregate price in the differentiatedgood sector declines following the reduction in offshoring costs, consumers reallocate expenditure from the homogeneous-good sector to the differentiated-good sector. The higher the elasticity of demand for differentiated goods, the higher the increase in expenditure on differentiated goods, and the more likely it is that the number of entrants and producing firms in the differentiated-good sector increases.

The net effect of a reduction in offshoring costs on employment in the differentiated-good sector can be decomposed into its extensive and intensive margin components. The extensive margin of employment refers to changes in employment due to births and deaths of firms, while the intensive margin of employment refers to changes in employment due to expansions and contractions of existing firms. We show that the net effect at the extensive margin crucially depends on the elasticity of demand for differentiated goods, while the net effect at the intensive margin crucially depends on the elasticity of substitution between inputs on the one hand, and the elasticity of substitution between differentiated-good varieties on the other.

Generally speaking, a low value of the elasticity of substitution between inputs (e.g., complementarity between offshored inputs and domestic labor) or a high value of elasticity of substitution between differentiated-good varieties is more conducive to net job creation for firms in the differentiated-good sector. Similarly, a high value of the elasticity of demand for differentiated goods, which implies a greater increase in the demand for differentiated goods following a reduction in offshoring costs, is more likely to lead to net job creation in the differentiated-good sector. Even though our model has a single differentiated-good sector with offshoring firms, its insights can be easily extended to a setting with multiple offshoring sectors. In particular, our results suggest that the impact of offshoring on employment will differ across sectors and will depend crucially on the (sectoral-level) elasticity parameters discussed above.

How these employment changes affect the economy-wide unemployment rate depends on two 
factors: the degree of search frictions in each sector and the change in the composition of the workforce. If the degree of search frictions is higher in the differentiated-good sector, then the unemployment rate is higher there as well. Now, if in response to a reduction in the cost of offshoring there is a decline in employment in the differentiated-good sector-so that workers move to the (lower unemployment) homogeneous-good sector-then the economy-wide unemployment rate decreases. In the opposite case where workers move to the differentiated-good sector, the economy-wide unemployment rate increases.

Irrespective of its impact on unemployment, offshoring always increases the welfare of the representative consumer. Intuitively, offshoring always leads to productivity improvements for the economy, which shows up in the form of a decline in the differentiated-good price index and, consequently, in an increase in welfare. Given our simplifying assumption of a representative household which diversifies away labor income risk, everyone gains from offshoring. However, this result needs to be treated with caution because in reality labor income risks are unlikely to be diversified away completely, and therefore, unemployed individuals are necessarily worse off than employed individuals; if offshoring increases unemployment, it necessarily makes some people - the newly unemployed-worse off.

Our model also allows us to study the implications of changes in search frictions and contrast them with the implications of a change in the offshoring cost. For example, a decrease in search frictions in the differentiated-good sector makes it cheaper to hire domestic labor in that sector and hence offshoring declines. Therefore, the impact on firm-level employment is similar to that of an increase in the cost of offshoring, with one difference: there is an additional positive effect on the domestic employment of all firms because the marginal cost of production for all differentiatedgood firms declines. Regarding the economy-wide unemployment rate, there are two forces at work. While the composition of the labor force matters (as was the case when the offshoring cost changed), now the unemployment rate in the differentiated-good sector declines as well, which contributes to a reduction in the economy-wide unemployment rate. Interestingly, a reduction in search frictions in the homogeneous-good sector increases the outside option of workers in the differentiated-good sector, making it more expensive for differentiated-good firms to hire domestic labor. This increases offshoring and thus, the implications for employment are the opposite of those for a decrease in search frictions in the differentiated-good sector.

To sum up, the key contribution of this paper lies in identifying the myriad channels through which offshoring affects employment at the firm and industry levels, as well as the economy-wide unemployment rate. In particular, it identifies three elasticity parameters - the elasticities of substitution in production and consumption for differentiated goods, and the elasticity of demand for 
the differentiated goods as a whole - which are crucial in determining the employment effects of offshoring and can guide the empirical research in this area. Contrary to popular perceptions, we show the possibility of offshoring having a positive effect on employment. As well, changes in search frictions affect sectoral employment and the economy-wide unemployment rate both directly and through their effect on offshoring. Interestingly, changes in search frictions in the two sectors have opposite employment effects.

The paper is organized as follows. Section 2 briefly reviews the theoretical and empirical literature on offshoring and employment. Section 3 introduces our model, while sections 4 and 5 present our main results for the impact of changes in offshoring costs and search frictions on jobs and unemployment. Section 6 presents a discussion and proposes extensions of our model. Lastly, section 7 concludes. A separate Appendix includes the proofs of the lemmas and propositions, and additional supporting material.

\section{Theoretical and Empirical Background}

Our modeling of offshoring by heterogeneous firms is informed by stylized facts. In our model there is a fixed cost of offshoring, a feature that we share with the workhorse offshoring model of Antràs and Helpman (2004). An implication is that only the most productive firms offshore, which is consistent with the stylized fact that importing firms are on average more productive and larger than purely domestic firms (see, e.g., Bernard, Jensen, Redding, and Schott, 2007 for the U.S.).

We go beyond Antràs and Helpman (2004) in postulating a production function with a continuum of inputs, with the set of offshored inputs being determined endogenously and responding to changes in offshoring costs. This is consistent with the evidence in Goldberg, Khandelwal, Pavcnik, and Topalova (2010), who find that a decline in input trade costs expands the set of imported intermediate inputs for Indian firms, which then translates into an increase in the number of final products they produce. Similarly, Gopinath and Neiman (2013) show that a large part of the import adjustment in response to a large currency depreciation in Argentina took the form of a decline in the number of imported inputs at the firm level. This channel, which Gopinath and Neiman (2013) call the sub-extensive margin of trade, can explain $45 \%$ of the decline in Argentina's imports, and is also responsible for the decline in firm-level productivity. Hence, their evidence is also supportive of the offshoring productivity effect obtained in our model. ${ }^{3}$

A recent empirical paper also suggests that the complementarity or substitutability between inputs is a crucial element in determining the labor market implications of offshoring. Using data

\footnotetext{
${ }^{3}$ There is further empirical support for the impact of offshoring on firm productivity. For example, Amiti and Konings (2007) (for Indonesia) and Topalova and Khandelwal (2011) (for India) find the positive effect of lower input tariffs on productivity to be much stronger than the effect of lower output tariffs.
} 
on the U.S. multinationals, Harrison and McMillan (2011) find that when the tasks performed by the subsidiary of a multinational are complementary to the tasks performed at home, offshoring leads to more job creation in the United States; however, offshoring causes job losses when the tasks performed in the subsidiary are substitutes for the tasks performed at home. This is consistent with our theoretical result that offshoring is more likely to cause job creation via the productivity effect if inputs are complementary.

Our paper is related to the growing literature on the impact of globalization on labor markets with search frictions. Pioneers of this literature are Carl Davidson and Steven Matusz, who in a series of papers study the implications of introducing unemployment arising from labor market frictions in trade models. As discussed in Davidson and Matusz (2004), their work has focused more on the roles of efficiency in job search, the rate of job destruction, and the rate of job turnover in the determination of comparative advantage. Moore and Ranjan (2005) show how trade liberalization in a skill-abundant country can reduce the unemployment of skilled workers and increase the unemployment of unskilled workers. Since each sector employs only one type of labor, there is no intersectoral reallocation of labor. Felbermayr, Prat, and Schmerer (2011) study the impact of a reduction in the cost of trading final goods on unemployment in a one-sector model with firm heterogeneity. Since their model has only one sector, there is no intersectoral reallocation of labor there either. Neither of these papers studies the implications of offshoring on unemployment.

Our structure with a homogeneous-good sector and a differentiated-good sector - with firm heterogeneity in the latter - is similar to the structure of Helpman and Itskhoki (2010), as is the use of a static model of search frictions. One difference in the modeling of labor market frictions is that while wages are determined by multilateral bargaining in the Helpman-Itskhoki model, we use the competitive-search approach of Shimer (1996) and Moen (1997) where firms post wages and workers direct their search. The most important difference, however, is that our main interest lies in studying the implications of offshoring on unemployment, while they study the implications of trade liberalization in final goods. As a result, we identify channels of influence arising from our offshoring structure - the job-relocation, productivity, and selection effects - that are absent in the Helpman-Itskhoki analysis. A recent paper by Felbermayr, Impullitti, and Prat (2014) introduces competitive search in a Melitz model to show how trade liberalization in final goods could lead to rising residual wage inequality. The presence of convex recruitment cost combined with wage posting generates a positive relationship between firm productivity and wages. Since our focus is on the employment effects of offshoring and not on wage inequality, we work with a linear recruitment cost. 
Mitra and Ranjan (2010) study the impact of offshoring on unemployment in a two-sector model similar to ours where firms in one of the two sectors offshore. Their offshoring structure is much simpler, with perfectly competitive firms producing with two inputs, only one of which can be offshored. Our production structure having a continuum of inputs with all of them being potentially offshorable - with the fraction of offshored inputs depending on offshoring costs - is more general. More importantly, the introduction of firm heterogeneity allows us to obtain the implications of offshoring at both the intensive and extensive margins of employment. Ranjan (2013) studies the role of wage-bargaining institutions in determining the impact of offshoring on unemployment. Neither of these papers has firm heterogeneity and therefore, cannot study the heterogeneous responses of firms to a change in the cost of offshoring. Davidson, Matusz, and Shevchenko (2008) also study the implications of offshoring in a job-search model, focusing on the impact of offshoring of high-tech jobs on low- and high-skilled workers' wages, and on overall welfare.

A related recent paper by Egger, Kreickemeier, and Wrona (2013) also studies the implications of offshoring in a model with firm heterogeneity. Their focus is on the implications of offshoring for inequality in the distribution of income, both within and between entrepreneurs and workers. They extend the model to allow for unemployment, which in their setting is driven by fair-wage considerations. Their Cobb-Douglas production function, same as in Antràs and Helpman (2004), restricts the model to the case of unitary elasticity of substitution between domestic labor and offshored inputs. In our set up, unemployment arises due to search frictions and our CES production function with a continuum of inputs allows us to study different degrees of substitution and complementarity between domestic labor and offshored inputs.

The offshoring structure in our model is related to the trade-in-tasks structure of the model of Grossman and Rossi-Hansberg (2008). While Grossman and Rossi-Hansberg (2008) assume perfect complementarity between tasks, we use a CES production function and show how the labor market implications depend crucially on the elasticity of substitution between inputs. ${ }^{4}$ Also, Grossman and Rossi-Hansberg (2008) do not have labor market frictions and they do not consider firm heterogeneity. Bernard, Redding, and Schott (2007) investigate the implications of finalgood trade liberalization for gross job flows in their Heckscher-Ohlin model with Melitz-type firm heterogeneity; however, neither do they have any labor market frictions nor do they study the impact of offshoring.

There is a growing empirical literature dealing with the impact of offshoring on employment.

\footnotetext{
${ }^{4}$ By assuming perfect complementarity between tasks, Grossman and Rossi-Hansberg (2008) work with the special case in which the offshoring productivity effect is maximum.
} 
The evidence is mixed. Görg (2011) provides a comprehensive survey of this literature. ${ }^{5}$ In addition, Wright (2014) uses U.S. manufacturing industry-level data and finds that offshoring decreases low-skill employment, increases high-skill employment, and has an overall positive effect on employment. He attributes these results to strong productivity effects and motivates his empirical exercise with a model à la Grossman-Rossi-Hansberg. ${ }^{6}$ Using establishment-level data from California, Groizard, Ranjan, and Rodriguez-Lopez (2014) find that a reduction in offshoring costs is associated with job destruction in the least productive establishments, job creation in the most productive establishments, and an increase in the death likelihood of the least productive establishments. These results are consistent with reduced-form firm-level predictions of our model.

Although the purpose of our paper is to understand the channels through which offshoring affects domestic employment, the model bears resemblance to the recent models of routine-task replacing technical change (as in the computerization model of Autor, Levy, and Murnane, 2003 or the task-approach discussed in Autor, 2013 and Autor and Dorn, 2013). In these models, as the price of computer capital declines, routine-intensive jobs are destroyed and the released workers reallocate to low-paying service occupations that are difficult to computerize. This is similar to the job-relocation effect of offshoring in our framework. In contrast to routine-task replacing models, however, our set-up considers firm heterogeneity, which combined with a fixed cost of offshoring generates a selection effect that divides firms into offshoring and non-offshoring firms. A consequence is that offshoring has differential effects on the labor demands of firms within the same industry.

\section{The Model}

In this section we present our model with labor market frictions, heterogeneous firms, and heterogeneous offshoring costs. The model assumes a country with two sectors: a differentiated-good sector and a homogeneous-good sector. Production in the homogeneous-good sector uses only domestic labor, but heterogeneous firms in the differentiated-good sector can offshore a fraction of their inputs to take advantage of lower foreign wages.

We begin by defining preferences and demand, then we discuss our search approach for the labor

\footnotetext{
${ }^{5}$ See the discussion of following works in Görg (2011): Görg and Hanley (2005) for Ireland, Ibsen, Warzynski, and Westergard-Nielsen (2010) for Denmark, Amiti and Wei (2005) for the U.K., Amiti and Wei (2009) for the U.S., Hijzen and Swaim (2007) for a multi-country study, and Wagner (2011) for Germany.

${ }^{6}$ As in our model, Wright (2014) assumes a production function with a continuum of inputs combined using a CES technology. The main difference with respect to our framework is that he does not consider either search frictions or firm heterogeneity, and hence, his model abstracts from unemployment analysis and all firms respond identically to reductions in offshoring costs (the selection effect is absent). As well, the assumption of Cobb-Douglas utility function in the two final goods makes his model unsuitable to analyze the role of elasticity of demand for the industry's product in determining the employment effect of offshoring.
} 
market, and describe the homogeneous- and differentiated-good sectors, with special attention to differentiated-good firms' offshoring decisions. Lastly, we define the equilibrium of this model and describe how the economy-wide unemployment rate is determined.

\subsection{Preferences and Demand}

The country is populated by a continuum of households in the unit interval. Households' preferences are defined over a continuum of differentiated goods and a homogeneous good. Following Helpman and Itskhoki (2010), we assume that the utility function for the representative household is given by

$$
\mathbb{U}=H+\frac{\eta}{\eta-1} Z^{\frac{\eta-1}{\eta}}
$$

where $H$ denotes the consumption of the homogeneous good, $Z=\left(\int_{\omega \in \Omega} z^{c}(\omega)^{\frac{\sigma-1}{\sigma}} d \omega\right)^{\frac{\sigma}{\sigma-1}}$ is the CES consumption aggregator of differentiated goods, and $\eta>1$ is the elasticity of demand for $Z$ ( $\eta$ also governs the substitutability between homogenous and differentiated goods). ${ }^{7}$ In $Z, z^{c}(\omega)$ denotes the consumption of variety $\omega, \Omega$ is the set of differentiated goods available for purchase, and $\sigma>1$ is the elasticity of substitution between differentiated-good varieties. It is assumed that $\sigma>\eta$ so that differentiated-good varieties are better substitutes for each other than for the homogeneous good. The homogeneous good is the numéraire-its price is 1 .

For differentiated goods, the representative household's demand for variety $\omega$ is given by $z^{c}(\omega)=$ $\frac{p(\omega)^{-\sigma}}{P^{1-\sigma}} P Z$, where $p(\omega)$ is the price of variety $\omega, P=\left[\int_{\omega \in \Omega} p(\omega)^{1-\sigma} d \omega\right]^{\frac{1}{1-\sigma}}$ is the price of the CES aggregator $Z$, and hence, $P Z$ is the aggregate spending on differentiated goods. Given the quasilinear utility function in (1), it follows that $Z=P^{-\eta}$, and therefore, the demand for variety $\omega$ can be rewritten as

$$
z^{c}(\omega)=p(\omega)^{-\sigma} P^{\sigma-\eta}
$$

It follows that the representative household spends $p(\omega) z^{c}(\omega)=p(\omega)^{1-\sigma} P^{\sigma-\eta}$ on this variety.

The representative household splits its expenditure, $E$, between homogeneous and differentiated goods. Given the quasi-linearity in (1), it follows that amount $E-P Z=E-P^{1-\eta}$ is spent on the homogeneous good. Therefore, the indirect utility function is given by

$$
\mathbb{V}=E+\frac{P^{1-\eta}}{\eta-1}
$$

which is increasing in spending, $E$, and decreasing in the differentiated-good price index, $P$. Given that there is a unit measure of identical households, equation (2) is also the market demand, $E$ is

\footnotetext{
${ }^{7}$ The qualitative results of this paper would be unchanged with a homothetic utility function (however, the algebra becomes tedious). The Appendix in Helpman and Itskhoki (2010) provides an outline of how to handle the case of homothetic utility.
} 
equivalent to the total expenditure in the economy, and $P Z$ is the country's total expenditure on differentiated goods.

\subsection{Labor Market and Search Frictions}

As in Helpman and Itskhoki (2010), each household is composed of a fixed supply of $\mathbb{L}$ workers, with each member willing to devote one unit of labor to production activities in either sector. Given that households are located in the unit interval, the total size of the country's workforce is also $\mathbb{L}$. We assume free mobility of workers across sectors.

Labor markets in both sectors are characterized by search frictions. While search frictions are traditionally introduced in a dynamic framework, Helpman and Itskhoki (2010) convincingly showed that the key insights in a model of trade with search frictions can be as easily generated using a static framework, and this is the approach we adopt. In our description of the labor market, the only difference from Helpman and Itskhoki (2010) is in wage setting: while they assume a multilateral-bargaining approach, we use the competitive-search approach pioneered by Shimer (1996) and Moen (1997) where firms post wages and workers direct their search. ${ }^{8}$

Firms post vacancies and wages to attract workers. The cost of posting a vacancy in sector- $i$, for $i \in\{H, Z\}$, is $\gamma_{i}$ units of the homogeneous good. Higher wages attract more workers, requiring less vacancies for each worker that a firm intends to hire. We assume that each firm $j$ in sector $i$, for $i \in\{H, Z\}$, decides to post a vacancy in a sub-market $i j$. Denote the number of vacancies posted by a firm $j$ in sector $i$ by $V_{i j}$, and the number of applicants attracted to the job by $U_{i j}$. The firm-worker matching function in sub-market $i j$ is given by

$$
M_{i j}\left(U_{i j}, V_{i j}\right)=m_{i} U_{i j}^{\beta} V_{i j}^{1-\beta}
$$

where $\beta \in[0,1]$. We define the job-finding probability of a worker in sub-market ij as

$$
a_{i j}\left(\theta_{i j}\right) \equiv \frac{M_{i j}\left(U_{i j}, V_{i j}\right)}{U_{i j}}=M_{i j}\left(1, \theta_{i j}\right)
$$

where $\theta_{i j} \equiv \frac{V_{i j}}{U_{i j}}$ is the labor market tightness in that sub-market. Given our Cobb-Douglas matching function, it follows that $a_{i j}\left(\theta_{i j}\right) \equiv m_{i} \theta_{i j}^{1-\beta}$. Also, the vacancy-filling probability of a firm in submarket $i j$ is

$$
q_{i j}\left(\theta_{i j}\right) \equiv \frac{M_{i j}\left(U_{i j}, V_{i j}\right)}{V_{i j}}=M_{i j}\left(\theta_{i j}^{-1}, 1\right)
$$

\footnotetext{
${ }^{8}$ Since we are working with large firms, if firms choose employment first and then enter into a wage negotiation with workers, firms have an incentive to strategically overhire workers as first pointed out by Stole and Zwiebel (1996). This makes wage determination analytically complicated, involving partial differential equations. The advantage of the wage-posting approach is that since firms post wages and vacancies simultaneously, there is no overhiring effect, which makes the model easy to solve. The results with wage bargaining are qualitatively similar.
} 
that is, $q_{i j}\left(\theta_{i j}\right) \equiv m_{i} \theta_{i j}^{-\beta}$ and $a_{i j}\left(\theta_{i j}\right)=q_{i j}\left(\theta_{i j}\right) \theta_{i j}$. In terms of the numéraire good, the wage rate offered by firm $j$ in sector $i$ is $w_{i j}$, and the cost of posting a vacancy in sector $i$ is $\gamma_{i}$.

Given that we follow the static labor-market approach of Helpman and Itskhoki (2010), we refer to $a_{i j}\left(\theta_{i j}\right)$ and $q_{i j}\left(\theta_{i j}\right)$ as strict probabilities. Note that $a_{i j}\left(\theta_{i j}\right)<1$ and $q_{i j}\left(\theta_{i j}\right)<1$ imply that

$$
m_{i}^{\frac{1}{\beta}}<\theta_{i j}<\frac{1}{m_{i}^{1 /(1-\beta)}} .
$$

As we will see below, condition (4) restricts the range of the parameters $m_{H}, m_{Z}, \gamma_{H}$, and $\gamma_{Z}$. These restrictions, however, do not affect any of our propositions or main results.

\subsection{The Homogeneous-Good Sector's Problem}

The market for the homogeneous good is perfectly competitive and the production of one unit of the good requires one unit of labor. We assume that there are single-worker firms in this sector. Since the price of the homogeneous good is 1, the homogeneous-good firm's profit maximization problem is equivalent to the following cost minimization problem:

$$
\min _{w_{H j}, \theta_{H j}}\left\{w_{H j}+\frac{\gamma_{H}}{q_{H j}\left(\theta_{H j}\right)}\right\} \text { s.t. } a_{H j}\left(\theta_{H j}\right) w_{H j} \geq \underline{w},
$$

where the firm chooses the wage to offer, $w_{H j}$, and the tightness in the sub-market, $\theta_{H j}$, so as to minimize its total labor costs. These costs are given by the sum of the wage paid to the worker and the total recruiting cost, $\gamma_{H} / q_{H j}$ (the firm must post $1 / q_{H j}$ vacancies to fill one job). The constraint in (5) states that the offered wage must be large enough so that the worker's expected income from a job in that sub-market, $a_{H j} w_{H j}$, is no less than the worker's outside opportunity, $\underline{w}$. Since the constraint always binds, the solution to the cost-minimization problem is given by

$$
w_{H j}=\left(\frac{\beta \gamma_{H}}{1-\beta}\right)^{1-\beta} \frac{\underline{w}^{\beta}}{m_{H}} \text { and } \theta_{H j}=\frac{(1-\beta) \underline{w}}{\beta \gamma_{H}} .
$$

Note that the solution is independent of $j$ and thus, we can drop the firm subscript $j$.

Since the market for the homogenous good is perfectly competitive, the equilibrium value of $\underline{w}$ is determined by the zero-profit condition: $1=w_{H}+\gamma_{H} / q_{H}\left(\theta_{H}\right)$. Substituting the expressions for $w_{H}$ and $\theta_{H}$ from above into the zero-profit condition we get

$$
\underline{w}=\left[\beta^{\beta}(1-\beta)^{1-\beta} m_{H} \gamma_{H}^{\beta-1}\right]^{\frac{1}{\beta}} .
$$

Lastly, using (7) we rewrite $w_{H}$ and $\theta_{H}$ as a function of the exogenous parameters:

$$
\begin{aligned}
& w_{H}=\beta \\
& \theta_{H}=(1-\beta)^{\frac{1}{\beta}}\left(\frac{m_{H}}{\gamma_{H}}\right)^{\frac{1}{\beta}} .
\end{aligned}
$$


The expression for $w_{H}$ is same as in the Nash bilateral-bargaining case if the worker's bargaining power is $\beta$. From (4) and (9), it follows that parameters $\gamma_{H}$ and $m_{H}$ must satisfy $\gamma_{H}<1-\beta$ and $m_{H}<\left[\gamma_{H} /(1-\beta)\right]^{1-\beta}<1$.

\subsection{Setup in the Differentiated-Good Sector}

\subsubsection{Production}

As in Melitz (2003), firms in the differentiated-good sector are heterogeneous in productivity. The productivity of a producer is denoted by $\varphi$, and the cumulative distribution function of the productivity levels of all differentiated-good firms is given by $G(\varphi)$, with the probability density function denoted by $g(\varphi)$. Each firm must pay a sunk entry cost of $f_{E}$ in units of the homogeneous good, after which it will observe its realization of productivity drawn from $G(\varphi)$.

Each differentiated good is produced using a continuum of inputs in the interval [0,1]. Inputs are ordered so that higher indexed inputs have a higher cost of offshoring; therefore, lower indexed inputs are offshored first. If a firm with productivity $\varphi$ offshores its inputs up to $\hat{\alpha}(\varphi)$, where $\hat{\alpha}(\varphi) \in[0,1]$, its production function is given by $z(\varphi)=\varphi Y(\varphi)$, where

$$
Y(\varphi)=\left(\int_{0}^{\hat{\alpha}(\varphi)} y^{*}(\alpha)^{\frac{\rho-1}{\rho}} d \alpha+\int_{\hat{\alpha}(\varphi)}^{1} y(\alpha)^{\frac{\rho-1}{\rho}} d \alpha\right)^{\frac{\rho}{\rho-1}}
$$

is a CES inputs aggregator. In $Y(\varphi),[0, \hat{\alpha}(\varphi)]$ denotes the range of offshored inputs, $y^{*}(\alpha)$ denotes the firm's requirement of foreign input $\alpha, y(\alpha)$ denotes the firm's requirement of domestic input $\alpha$, and $\rho \geq 0$ is the elasticity of substitution/complementarity between inputs-inputs are gross complements if $\rho \in[0,1)$, they are gross substitutes if $\rho>1$, and they are neither substitutes nor complements if $\rho=1(Y(\varphi)$ becomes the Cobb-Douglas function). As we show later, the issue of whether inputs are complements or substitutes plays a crucial role in our results. By allowing the degree of complementarity/substitutability across inputs to vary, our approach generalizes the structure of Grossman and Rossi-Hansberg (2008), who focus their analysis on the case of perfect complementarity $(\rho=0)$.

There are fixed and variable costs of offshoring inputs. If the firm with productivity $\varphi$ decides to offshore, so that $\hat{\alpha}(\varphi)>0$, it must pay a fixed cost of $f_{o}$ in units of the homogeneous good. In addition, the firm requires foreign labor to meet variable offshoring costs. The cost of hiring a unit of foreign labor is $w^{*}$. We assume that one unit of foreign labor is not identical to one unit of domestic labor. In particular, to obtain one unit of input $\alpha$, a firm either employs one unit of domestic labor, or $\lambda k(\alpha)>1$ units of foreign labor. That is, $y(\alpha)=\ell$ and $y^{*}(\alpha)=\frac{\ell^{*}}{\lambda k(\alpha)}$, where $\ell$ and $\ell^{*}$ denote, respectively, units of domestic and foreign labor. As in the model of Grossman 
and Rossi-Hansberg (2008), the term $\lambda k(\alpha)$ accounts for the additional costs of making foreignproduced input $\alpha$ compatible with domestic inputs. It involves a general component, $\lambda$, and an input-specific component, $k(\alpha)$. The inputs are ordered by their offshoring cost so that $k(\alpha)$ is strictly increasing in $\alpha$.

\subsubsection{Profit Maximization}

Each differentiated-good firm decides whether to offshore or not. Having decided to offshore, the firm decides on what fraction of inputs to offshore, how much domestic and foreign labor to hire, what wage to post for domestic workers, and which sub-market to post its vacancies in. We establish the following lemma for a firm with productivity $\varphi$.

Lemma 1. Let $\hat{\alpha}(\varphi)$ be the fraction of inputs offshored by a firm with productivity $\varphi$, and let $L$ and $L^{*}$ denote the total amounts of domestic and foreign labor employed for the production of the composite input $Y(\varphi)$. Then

$$
Y(\varphi)=\left[\kappa(\varphi) L^{* \frac{\rho-1}{\rho}}+v(\varphi) L^{\frac{\rho-1}{\rho}}\right]^{\frac{\rho}{\rho-1}}
$$

where $\kappa(\varphi) \equiv \lambda^{\frac{1-\rho}{\rho}} K[\hat{\alpha}(\varphi)]^{\frac{1}{\rho}}, K[\hat{\alpha}(\varphi)]=\int_{0}^{\hat{\alpha}(\varphi)} k(\alpha)^{1-\rho} d \alpha$, and $v(\varphi) \equiv[1-\hat{\alpha}(\varphi)]^{\frac{1}{\rho}}$.

The profit-maximization problem for a differentiated-good firm with productivity $\varphi$ is

$$
\max _{\hat{\alpha}(\varphi), L, L^{*}, w_{Z}(\varphi), \theta_{Z}(\varphi)}\left\{p(\varphi) \varphi Y(\varphi)-w^{*} L^{*}-\left[w_{Z}(\varphi)+\frac{\gamma_{Z}}{q_{Z}\left[\theta_{Z}(\varphi)\right]}\right] L\right\} \text { s.t. } a_{Z}\left[\theta_{Z}(\varphi)\right] w_{Z}(\varphi) \geq \underline{w},
$$

where $Y(\varphi)$ is given by (11). In the above expression, the total cost of a unit of domestic labor for a firm with productivity $\varphi$ is given by the wage, $w_{Z}(\varphi)$, plus the recruiting cost, $\gamma_{Z} / q_{Z}\left[\theta_{Z}(\varphi)\right]$. Note that the worker's outside opportunity in the constraint in (12) is again $\underline{w}$. This is due to our free-mobility assumption, which implies that workers are indifferent between searching in either sector.

From the maximization problem in (12), note that irrespective of the amount of domestic labor, $L$, that a firm hires, it will always minimize the cost of hiring a unit of domestic labor. That is, the firm solves

$$
\min _{w_{Z}(\varphi), \theta_{Z}(\varphi)}\left\{w_{Z}(\varphi)+\frac{\gamma_{Z}}{q_{Z}\left[\theta_{Z}(\varphi)\right]}\right\} \text { s.t. } a_{Z}\left[\theta_{Z}(\varphi)\right] w_{Z}(\varphi) \geq \underline{w} .
$$

Since the outside opportunity of workers, $\underline{w}$, is predetermined, it is easily verified that $w_{Z}(\varphi)$ and $\theta_{Z}(\varphi)$ are independent of $\varphi$. Using (7) we obtain the following solution for $w_{Z}$ and $\theta_{Z}$ :

$$
\begin{aligned}
& w_{Z}=\frac{\beta m_{H}}{m_{Z}}\left(\frac{\gamma_{Z}}{\gamma_{H}}\right)^{1-\beta} \\
& \theta_{Z}=\frac{1}{\gamma_{Z}}\left[\frac{(1-\beta) m_{H}}{\gamma_{H}^{1-\beta}}\right]^{\frac{1}{\beta}} .
\end{aligned}
$$


From (4) and (15), the search parameters $m_{Z}$ and $\gamma_{Z}$ must satisfy $m_{Z}<1$ and

$$
\left[\frac{(1-\beta) m_{H}}{\gamma_{H}^{1-\beta}}\right]^{\frac{1}{\beta}} m_{Z}^{\frac{1}{1-\beta}}<\gamma_{Z}<\left[\frac{(1-\beta) m_{H}}{\gamma_{H}^{1-\beta} m_{Z}}\right]^{\frac{1}{\beta}}
$$

Let $\hat{w}_{Z}$ denote the total cost of a unit of domestic labor; that is, $\hat{w}_{Z}=w_{z}+\gamma_{Z} / q_{Z}\left(\theta_{Z}\right)$. Given that $q_{Z}\left(\theta_{Z}\right)=m_{Z} \theta_{Z}^{-\beta}$, and using equations (14) and (15), it follows that

$$
\hat{w}_{Z}=\frac{m_{H}}{m_{Z}}\left(\frac{\gamma_{Z}}{\gamma_{H}}\right)^{1-\beta} .
$$

That is, the cost of hiring a unit of domestic labor declines if either the matching efficiency increases ( $\uparrow$ in $\left.m_{Z}\right)$ or the vacancy cost decreases $\left(\downarrow\right.$ in $\left.\gamma_{Z}\right)$ in the differentiated-good sector. In other words, a reduction in search frictions in the differentiated-good sector lowers the cost of hiring labor in that sector. The opposite happens when search frictions decrease in the homogeneous-good sector ( $\uparrow$ in $m_{H}$ or $\downarrow$ in $\gamma_{H}$ ) because it raises the outside option of workers engaged in the differentiated-good sector.

Note from (16) that in the special case when the labor market parameters are identical across sectors $\left(m_{H}=m_{Z}, \gamma_{H}=\gamma_{Z}\right)$ then $\hat{w}_{Z}=1$, so that the cost of hiring a unit of labor is identical across the two sectors. More generally, given the parameters governing search frictions in the two sectors $\left(m_{H}, m_{Z}, \gamma_{H}, \gamma_{Z}\right.$, and $\left.\beta\right)$, the labor market outcomes of interest, $w_{H}, \theta_{H}, w_{Z}, \theta_{Z}$, and $\hat{w}_{Z}$, are determined by (8), (9), (14), (15), and (16).

Since the cost of hiring domestic labor in the differentiated-good sector, $\hat{w}_{z}$, is independent of $\varphi$-as is the cost of hiring foreign labor, $w^{*}$ - the differentiated-good firm's profit-maximization problem in (12) yields a standard mark-up pricing over the firm's marginal cost. To obtain the marginal cost for a firm with productivity $\varphi$, we need to know first the cost of a unit of $Y(\varphi)$. Nonoffshoring firms hire only domestic labor: $\hat{\alpha}(\varphi)=0$ and thus equation (11) collapses to $Y(\varphi)=L$ for these firms. Hence, the cost of one unit of $Y(\varphi)$ for non-offshoring firms is simply $\hat{w}_{Z}$. The following lemma shows the value of $\hat{\alpha}(\varphi)$ and the cost of one unit of $Y(\varphi)$ for offshoring firms.

Lemma 2. For offshoring firms $\hat{\alpha}(\varphi)=\hat{\alpha}$ and the cost of one unit of $Y(\varphi)$ is $c(\hat{\alpha}) \hat{w}_{z}$, where

$$
\begin{aligned}
& \hat{\alpha}=k^{-1}\left(\frac{\hat{w}_{Z}}{\lambda w^{*}}\right) \\
& c(\hat{\alpha})=\left[k(\hat{\alpha})^{\rho-1} K(\hat{\alpha})+1-\hat{\alpha}\right]^{\frac{1}{1-\rho}} .
\end{aligned}
$$

For $\hat{\alpha}>0, c(\hat{\alpha}) \in\left(w^{*} / \hat{w}_{z}, 1\right), c^{\prime}(\hat{\alpha})<0$, and $c(\hat{\alpha}) \hat{w}_{z} \in\left(w^{*}, \hat{w}_{z}\right)$.

Equation (17) simply says that the marginal cost of offshoring input $\hat{\alpha}$, given by $\lambda k(\hat{\alpha}) w^{*}$, equals the cost of producing it using domestic labor, $\hat{w}_{z}$. Therefore, an offshoring firm offshores 
input $\alpha$ if and only if $\lambda k(\alpha) w^{*} \leq \hat{w}_{z}$. Since $k^{-1 \prime}(\cdot)>0$, a decline in $\lambda$ or $w^{*}$ makes offshoring more attractive and hence $\hat{\alpha}$ increases. ${ }^{9}$ As well, domestic labor market institutions affect the extent of offshoring - any factor that raises $\hat{w}_{z}$ increases $\hat{\alpha}$. The lemma above also shows that all offshoring firms offshore the same fraction of inputs $\hat{\alpha}$. However, larger firms offshore more in absolute terms. ${ }^{10}$

\subsubsection{Pricing}

Since the cost of a unit of $Y(\varphi)$ is $\hat{w}_{z}$ for non-offshoring firms, the marginal cost of producing differentiated goods for a non-offshoring firm with productivity $\varphi$ is $\frac{\hat{w}_{Z}}{\varphi}$. From Lemma 2, the marginal cost for an offshoring firm with productivity $\varphi$ is $\frac{c(\hat{\alpha}) \hat{w}_{Z}}{\varphi}$. The term $c(\hat{\alpha})$ accounts for the Grossman-Rossi-Hansberg offshoring productivity effect: by offshoring a fraction of its inputs, the marginal cost of a firm with productivity $\varphi$ is lower than the firm's marginal cost if it only employs domestic labor, $\frac{c(\hat{\alpha}) \hat{w}_{Z}}{\varphi}<\frac{\hat{w}_{Z}}{\varphi}$.

Given the fixed cost of offshoring, $f_{o}$, there exists an offshoring cutoff productivity level, $\hat{\varphi}_{o}$, such that a firm offshores if and only if its productivity is no less than $\hat{\varphi}_{o}$. Therefore, the price set by a firm with productivity $\varphi$ can be written as

$$
p(\varphi)=\left(\frac{\sigma}{\sigma-1}\right) \frac{c(\hat{\alpha})^{\mathbb{I}\left\{\varphi \geq \hat{\varphi}_{o}\right\}} \hat{w}_{Z}}{\varphi},
$$

where $\mathbb{I}\left\{\varphi \geq \hat{\varphi}_{o}\right\}$ is an indicator function taking the value of 1 if $\varphi \geq \hat{\varphi}_{o}$, and zero otherwise. Using the price equation in (19) and the market demand function for each variety in (2), we obtain the following expression for the firm's gross profit function (before deducting fixed costs):

$$
\pi(\varphi)=\frac{p(\varphi)^{1-\sigma} P^{\sigma-\eta}}{\sigma}
$$

Note that $p^{\prime}(\varphi)<0$ and $\pi^{\prime}(\varphi)>0$, so that more productive firms charge lower prices and have larger profits.

\footnotetext{
${ }^{9}$ Corner solutions exist if $(i) \lambda k(0) w^{*} \geq \hat{w}_{Z}$, so that $\hat{\alpha}=0$ and domestic firms never offshore, or (ii) $\lambda k(1) w^{*} \leq \hat{w}_{Z}$, so that $\hat{\alpha}=1$ and domestic firms only employ foreign labor. For simplicity, in our analysis we only consider interior solutions.

${ }^{10}$ Gopinath and Neiman (2013) find evidence from Argentina that larger firms offshore a larger fraction of inputs. As in their theoretical model, we can use input-level fixed costs to generate the result that larger firms offshore a greater fraction of inputs. Let us assume that there is a fixed cost, $f_{I}$, associated with the offshoring of input $I$. Now, the firm's indifference condition between offshoring and procuring an input domestically is given by $\lambda k[\hat{\alpha}(\varphi)] w^{*} l(\varphi)+f_{I}=$ $l(\varphi) \hat{w}_{Z}$, where $l(\varphi)$ is the quantity purchased of this particular input, and $\hat{\alpha}(\varphi)$ is the input for which the cost of domestic production (right-hand side) equals the cost of offshoring (left-hand side). We can rewrite the above equation as $k[\hat{\alpha}(\varphi)]=\left[1 /\left(\lambda w^{*}\right)\right]\left[\hat{w}_{Z}-f_{I} / l(\varphi)\right]$. Also, $l^{\prime}(\varphi)>0$ since more productive firms sell more output. Therefore, $\hat{\alpha}(\varphi)$ is increasing in $\varphi$, i.e. $\hat{\alpha}^{\prime}(\varphi)>0$ : more productive firms offshore a greater fraction of inputs. Under this approach, however, the model's tractability is reduced significantly and offshoring affects employment through the same channels we will identify below.
} 


\subsubsection{Cutoff Productivity Levels}

For every producing firm, there is a fixed cost of operation, $f$, in units of the homogeneous good. Hence, besides the cutoff productivity level that separates offshoring and non-offshoring firms, $\hat{\varphi}_{o}$, there exists a cutoff level $\hat{\varphi}$ that determines whether or not a firm produces: firms with productivity levels below $\hat{\varphi}$ do not produce because their gross profits are not large enough to cover the fixed cost of operation. Thus, $\hat{\varphi}$ is defined as the level of productivity such that $\pi(\hat{\varphi})=f$.

Assuming that $\hat{\varphi}<\hat{\varphi}_{o}$, so that there is a set of firms with productivity levels between $\hat{\varphi}$ and $\hat{\varphi}_{o}$ which produce but do not offshore, we get from equation (19) that $p(\hat{\varphi})=\left(\frac{\sigma}{\sigma-1}\right) \frac{\hat{w}_{Z}}{\hat{\varphi}}$. Substituting $p(\hat{\varphi})$ into equation $(20)$ to obtain $\pi(\hat{\varphi})$, we can write the zero-cutoff-profit condition as

$$
P=(\sigma f)^{\frac{1}{\sigma-\eta}}\left[\left(\frac{\sigma}{\sigma-1}\right) \frac{\hat{w}_{Z}}{\hat{\varphi}}\right]^{\frac{\sigma-1}{\sigma-\eta}} .
$$

Moreover, using (19) and (21) we can conveniently rewrite $\pi(\varphi)$ as

$$
\pi(\varphi)=\left(\frac{\varphi}{c(\hat{\alpha})^{\mathbb{I}\left\{\varphi \geq \hat{\varphi}_{o}\right\}} \hat{\varphi}}\right)^{\sigma-1} f
$$

for $\varphi \geq \hat{\varphi}$. From Lemma 2 we know that $c(\hat{\alpha}) \in\left(w^{*} / \hat{w}_{z}, 1\right)$; therefore, the gross profit function (which is increasing in $\varphi$ ) jumps up in $\hat{\varphi}_{o}$.

As $\hat{\varphi}_{o}$ separates out non-offshoring and offshoring firms, a firm with productivity $\hat{\varphi}_{o}$ must be indifferent between offshoring and not offshoring. Using equation (22), this indifference condition can be written as

$$
\left(\frac{\hat{\varphi}_{o}}{c(\hat{\alpha}) \hat{\varphi}}\right)^{\sigma-1} f-f-f_{o}=\left(\frac{\hat{\varphi}_{o}}{\hat{\varphi}}\right)^{\sigma-1} f-f .
$$

The left-hand side shows the net profit of an offshoring firm with productivity $\hat{\varphi}_{o}$ (both fixed costs of operation, $f$, and fixed costs of offshoring, $f_{o}$, are deducted from gross profits, $\pi\left(\hat{\varphi}_{o}\right)$ ), and the right-hand side shows its net profit if it had decided not to offshore (its gross profit is lower but it does not have to pay the fixed costs of offshoring).

From the indifference condition, it follows that the relationship between the cutoff productivities $\hat{\varphi}_{o}$ and $\hat{\varphi}$ is given by

$$
\hat{\varphi}_{o}=B \Gamma(\hat{\alpha}) \hat{\varphi}
$$

where $B \equiv\left(f_{o} / f\right)^{\frac{1}{\sigma-1}}$ and

$$
\Gamma(\hat{\alpha}) \equiv\left[\frac{c(\hat{\alpha})^{\sigma-1}}{1-c(\hat{\alpha})^{\sigma-1}}\right]^{\frac{1}{\sigma-1}} .
$$

Note that in order for $\hat{\varphi}<\hat{\varphi}_{o}$, we need to satisfy $B \Gamma(\hat{\alpha})>1$, which we assume to be the case (a sufficient condition is $\left.c(1)>\left[f /\left(f_{o}+f\right)\right]^{\frac{1}{\sigma-1}}\right)$. Given that $c^{\prime}(\hat{\alpha})<0$, it follows that $\Gamma^{\prime}(\hat{\alpha})<0$ : the greater the productivity benefits of offshoring - as captured by a higher $\hat{\alpha}$ and a lower $c(\hat{\alpha})$ - the 
smaller the gap between the offshoring cutoff and the zero-profit cutoff. As shown by $B$, the gap between $\hat{\varphi}$ and $\hat{\varphi}_{o}$ increases with the fixed cost of offshoring, $f_{o}$, and declines with the fixed cost of operation, $f$.

\subsubsection{Free-Entry Condition and the Mass of Firms}

A potential firm will enter if the value of entry is no less than the required sunk entry cost, $f_{E}$. The potential entrant knows its productivity only after entry, and hence, the pre-entry expected profit is

$$
\Pi \equiv \int_{\hat{\varphi}}^{\hat{\varphi}_{o}}[\pi(\varphi)-f] g(\varphi) d \varphi+\int_{\hat{\varphi}_{o}}^{\infty}\left[\pi(\varphi)-f-f_{o}\right] g(\varphi) d \varphi
$$

The free-entry condition is then

$$
\Pi=f_{E}
$$

The mass of producing firms in the differentiated-good sector is denoted by $N$. Following the static version of the Melitz model of Melitz and Redding (2013), it is the case that the mass of producing firms is the fraction of entrants with productivity draws no less than $\hat{\varphi}$; that is,

$$
N=[1-G(\hat{\varphi})] N_{E}
$$

where $N_{E}$ denotes the mass of entrants. Let $s \in\{n, o\}$ denote offshoring status, with $n$ meaning "not offshoring" and $o$ meaning "offshoring". If $N_{s}$ represents the mass of firms with offshoring status $s$, it must be the case that $N=N_{n}+N_{o}$ and

$$
\begin{aligned}
& N_{n}=\left[G\left(\hat{\varphi}_{o}\right)-G(\hat{\varphi})\right] N_{E} \\
& N_{o}=\left[1-G\left(\hat{\varphi}_{o}\right)\right] N_{E} .
\end{aligned}
$$

To obtain $N_{n}, N_{o}$, and $N$ in terms of $\hat{w}_{Z}, \hat{\alpha}, \hat{\varphi}$ and $\hat{\varphi}_{o}$, we need to obtain an expression for $N_{E}$. Section $\mathrm{A}$ in the Appendix derives $N_{E}$ along with market-share expressions for non-offshoring and offshoring firms.

\subsubsection{Employment}

We now turn our attention to the determination of employment in the differentiated-good sector. Offshoring firms demand foreign labor for the inputs in the range $[0, \hat{\alpha}]$ and domestic labor in the range $(\hat{\alpha}, 1]$. On the other hand, non-offshoring firms demand only domestic labor. Let $L_{s}(\varphi)$ denote the demand for domestic labor of a firm with productivity $\varphi$ and offshoring status $s$, for $s \in\{n, o\}$. The following lemma shows the expressions for $L_{n}(\varphi)$ and $L_{o}(\varphi)$. 


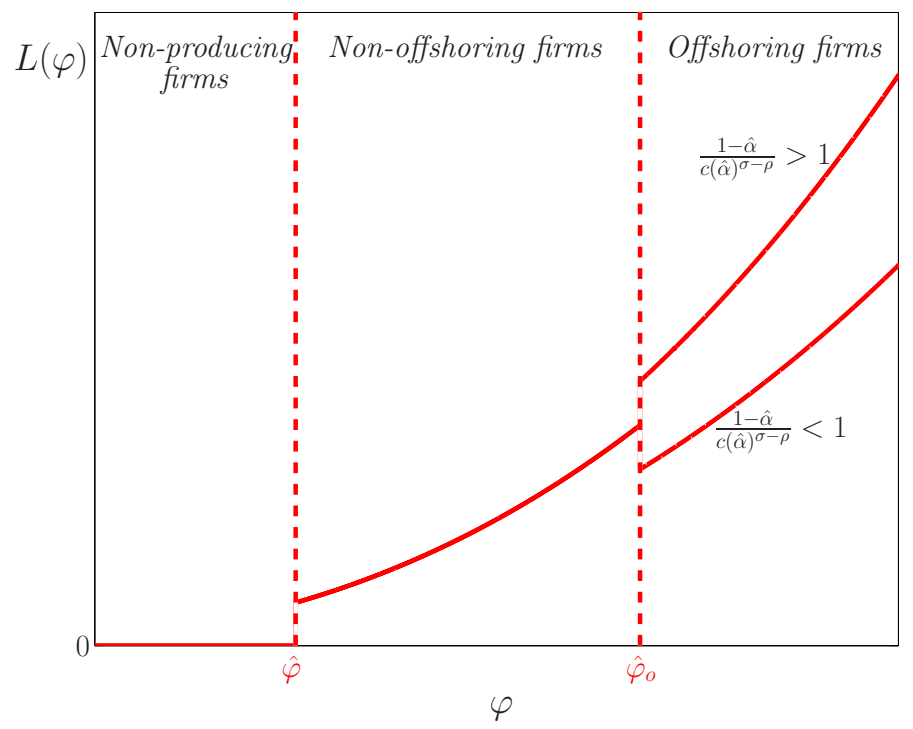

Figure 1: Firm-level demand for domestic labor and productivity

Lemma 3. The demand for domestic labor of a firm with productivity $\varphi \geq \hat{\varphi}$ and offshoring status $s$, for $s \in\{n, o\}$, is given by

$$
L_{s}(\varphi)= \begin{cases}\frac{(\sigma-1)}{\hat{w}_{Z}}\left(\frac{\varphi}{\hat{\varphi}}\right)^{\sigma-1} f & \text { if } s=n \\ \frac{(1-\hat{\alpha})(\sigma-1)}{c(\hat{\alpha})^{\sigma-\rho} \hat{w}_{Z}}\left(\frac{\varphi}{\hat{\varphi}}\right)^{\sigma-1} f & \text { if } s=o .\end{cases}
$$

For $\varphi \geq \hat{\varphi}$ and for firms with the same offshoring status $s$, note that $L_{s}(\varphi)$ is increasing in productivity, $\varphi$, and decreasing in the unit cost of domestic labor, $\hat{w}_{z}$. Letting $L(\varphi)$ denote the demand for domestic labor of a firm with productivity $\varphi$, it follows that

$$
L(\varphi)= \begin{cases}0 & \text { if } \varphi<\hat{\varphi} \\ L_{n}(\varphi) & \text { if } \varphi \in\left[\hat{\varphi}, \hat{\varphi}_{o}\right) \\ L_{o}(\varphi) & \text { if } \varphi \geq \hat{\varphi}_{o}\end{cases}
$$

Figure 1 shows $L(\varphi)$. From (30) note that $\frac{L_{o}(\varphi)}{L_{n}(\varphi)}=\frac{1-\hat{\alpha}}{c(\hat{\alpha})^{\sigma-\rho}}$, and thus, the demand for domestic labor of a firm with productivity $\hat{\varphi}_{o}$ jumps up or down depending on whether $\frac{1-\hat{\alpha}}{c(\hat{\alpha})^{\sigma-\rho}}$ is greater or less than 1 . The term $1-\hat{\alpha}<1$ is the fraction of inputs that an offshoring firm obtains domestically, and the term $\frac{1}{c(\hat{\alpha})^{\sigma-\rho}}$ (which is greater than 1 if $\sigma>\rho$ ) is associated with the productivity gains from offshoring. Hence, $L(\varphi)$ jumps up at $\hat{\varphi}_{o}$ if $\sigma>\rho$ and the productivity-gain effect is stronger than the effect of the relocation of fraction $\hat{\alpha}$ of inputs; otherwise, $L(\varphi)$ jumps down at $\hat{\varphi}_{o}$.

We can also obtain an expression for aggregate domestic employment in the differentiated-good sector. Let $\bar{L}_{s}$ denote the average domestic employment of producing firms with offshoring status $s$, so that $\bar{L}_{n}=\int_{\hat{\varphi}}^{\hat{\varphi}_{o}} L_{n}(\varphi) g\left(\varphi \mid \hat{\varphi} \leq \varphi<\hat{\varphi}_{o}\right) d \varphi$ and $\bar{L}_{o}=\int_{\hat{\varphi}_{o}}^{\infty} L_{o}(\varphi) g\left(\varphi \mid \varphi \geq \hat{\varphi}_{o}\right) d \varphi$. The total employment of domestic labor in the differentiated-good sector is then given by

$$
L_{Z}=N_{n} \bar{L}_{n}+N_{o} \bar{L}_{o},
$$


where $N_{n} \bar{L}_{n}$ is the domestic employment of producing non-offshoring firms, and $N_{o} \bar{L}_{o}$ is the domestic employment of offshoring firms. Given that $g\left(\varphi \mid \hat{\varphi} \leq \varphi<\hat{\varphi}_{o}\right)=\frac{g(\varphi)}{G\left(\hat{\varphi}_{o}\right)-G(\hat{\varphi})}, g(\varphi \mid \hat{\varphi} \geq$ $\left.\hat{\varphi}_{o}\right)=\frac{g(\varphi)}{1-G\left(\hat{\varphi}_{o}\right)}$, and using the expressions for $N_{n}$ and $N_{o}$ in (28) and (29), we rewrite $L_{z}$ as

$$
L_{Z}=N_{E}\left[\int_{\hat{\varphi}}^{\hat{\varphi}_{o}} L_{n}(\varphi) g(\varphi) d \varphi+\int_{\hat{\varphi}_{o}}^{\infty} L_{o}(\varphi) g(\varphi) d \varphi\right] .
$$

The expression inside the square bracket on the right-hand side of (32) is a potential entrant's expected domestic employment, so that changes in $L_{Z}$ comprise either changes in the mass of entrants (as it directly affects the masses of non-offshoring and offshoring firms) or changes in expected firm-level domestic employment.

In the analysis below, we use equations (30) and (32) to understand the different channels through which offshoring costs and labor-market search frictions affect employment in the differentiated good sector.

\subsection{Equilibrium and the Unemployment Rate}

Let us now define this model's equilibrium and the economy-wide unemployment rate.

Definition 1. Given $\pi(\varphi)$ and $\Pi$ in (22) and (25), an equilibrium is a 4-tuple $\left(\hat{w}_{z}, \hat{\alpha}, \hat{\varphi}, \hat{\varphi}_{o}\right)$ that solves (16), (17), (23), and (26). The equilibrium exists and is unique. ${ }^{11}$

The economy-wide unemployment rate is a weighted average of sectoral unemployment rates, with the weights given by the share of workers searching in each sector. The sectoral unemployment rates are determined by search-friction parameters. In particular, the unemployment rate in sector $i$, for $i \in\{H, Z\}$, is

$$
u_{i}=1-a_{i}\left(\theta_{i}\right)
$$

Recall that $a_{i}\left(\theta_{i}\right) \equiv m_{i} \theta_{i}^{1-\beta}$ is the job-finding probability in sector $i$, with $\theta_{i}$ denoting the sector's labor market tightness. Denote the number of workers who decide to search in sector $i$ by $\mathbb{L}_{i}$, so that

$$
\mathbb{L}=\mathbb{L}_{H}+\mathbb{L}_{Z}
$$

Hence, the economy-wide unemployment rate, $u$, is

$$
u=u_{H} \frac{\mathbb{L}_{H}}{\mathbb{L}}+u_{Z} \frac{\mathbb{L}_{Z}}{\mathbb{L}}
$$

The expression for $u$ is similar to the one derived by Helpman and Itskhoki (2010). As in their model, given that $\mathbb{L}$ is fixed, the economy-wide unemployment rate increases either when more workers

\footnotetext{
${ }^{11}$ See proof of existence and uniqueness of equilibrium in section B in the Appendix.
} 
search in the sector with the higher unemployment rate or when the sectoral unemployment rate rises in either sector.

For $\mathbb{L}_{Z}$ and $\mathbb{L}_{H}$, note first that it must be the case that $L_{i}=\left(1-u_{i}\right) \mathbb{L}_{i}$ for $i \in\{H, Z\}$, where $L_{i}$ is the amount of labor employed in sector $i$. Therefore

$$
\mathbb{L}_{Z}=\frac{L_{z}}{1-u_{z}}
$$

where $L_{Z}$ is given by (32). $\mathbb{L}_{H}$ is then determined from (34), which then implies that the amount of labor employed in the homogeneous-good sector is calculated as

$$
L_{H}=\left(1-u_{H}\right)\left(\mathbb{L}-\frac{L_{Z}}{1-u_{Z}}\right) .
$$

Lastly, the aggregate income of workers is given by $w_{H} L_{H}+w_{Z} L_{Z}$, which must be equivalent to total expenditure, $E$. Using (33), (36) and (37), along with the condition $a_{H} w_{H}=a_{Z} w_{Z}=\underline{w}$ (ensured by the assumption of free intersectoral mobility of labor), it can be verified that

$$
E \equiv w_{H} L_{H}+w_{Z} L_{Z}=\underline{w} \mathbb{L}
$$

That is, the aggregate labor income of a household - and hence of the entire country - is simply a product of the expected labor income for each member of the household, $\underline{w}$, and the number of members of the household, $\mathbb{L}$.

\section{Offshoring Costs, Job Flows, and Unemployment}

In this section we discuss the model's implications for the effects of a change in offshoring costs on firm- and industry-level employment in the differentiated-good sector as well as on the economywide unemployment rate.

Our measures of offshoring costs are the general component of the variable cost of offshoring inputs, $\lambda$, and the fixed cost of offshoring inputs, $f_{o}$. Recall that the offshoring cost of a unit of input $\alpha$ is $\lambda k(\alpha) w^{*}$ for $\alpha \in[0,1]$ (where $k(\alpha)$ is the input-specific component of the offshoring cost), so that a decrease in $\lambda$ implies a proportional decline in the offshoring costs of all inputs. We focus on the impact of a change in $\lambda$, and leave the discussion of a change in $f_{o}$ for section $\mathrm{D}$ in the Appendix.

\subsection{Firm-Level Employment Responses}

For an existing firm with productivity $\varphi$ that does not change its offshoring status $s$ after a change in $\lambda$, its labor demand response is entirely accounted for by changes in $L_{s}(\varphi)$, which is defined in 
(30) in Lemma 3 . Hence, for these firms we can look at the elasticity of $L_{s}(\varphi)$ with respect to $\lambda$, $\zeta_{L_{s}(\varphi), \lambda}$, which is given by

$$
\zeta_{L_{s}(\varphi), \lambda}= \begin{cases}-(\sigma-1) \zeta_{\hat{\varphi}, \lambda} & \text { if } s=n \\ -\frac{\hat{\alpha}}{1-\hat{\alpha}} \zeta_{\hat{\alpha}, \lambda}-(\sigma-\rho) \zeta_{c(\hat{\alpha}), \lambda}-(\sigma-1) \zeta_{\hat{\varphi}, \lambda} & \text { if } s=o,\end{cases}
$$

where $\zeta_{\hat{\varphi}, \lambda}, \zeta_{\hat{\alpha}, \lambda}$, and $\zeta_{c(\hat{\alpha}), \lambda}$ also denote elasticities. The following lemma presents the signs of these elasticities.

Lemma 4. $\zeta_{\hat{\alpha}, \lambda}<0, \zeta_{c(\hat{\alpha}), \lambda}>0, \zeta_{\hat{\varphi}, \lambda}<0, \zeta_{\hat{\varphi}_{o}, \lambda}>0$. Moreover, $\zeta_{c(\hat{\alpha}), \lambda}>-\zeta_{\hat{\varphi}, \lambda}$.

A decline in the variable cost of offshoring leads to a greater fraction of inputs being offshored; that is, $\zeta_{\hat{\alpha}, \lambda}<0$. Since the jobs associated with the production of these inputs are relocated abroad, we use the term "job relocation" to refer to this effect on domestic labor demand. In equation (39) the job-relocation effect is given by $-\frac{\hat{\alpha}}{1-\hat{\alpha}} \zeta_{\hat{\alpha}, \lambda}>0$, and thus, after a decline in $\lambda$ this effect is a source of domestic job losses for offshoring firms.

A decline in the offshoring cost also improves the productivity of firms engaged in offshoring: their marginal costs $\left(c(\hat{\alpha}) \hat{w}_{z} / \varphi\right)$ decline, as they can purchase inputs abroad at a lower cost: $\zeta_{c(\hat{\alpha}), \lambda}>0$. The lower marginal cost allows these firms to charge lower prices and increase their market shares. We call the impact of the increased productivity on the demand for domestic labor the "productivity effect". In equation (39) the productivity effect is given by $-(\sigma-\rho) \zeta_{c(\hat{\alpha}), \lambda}$. Note that whether the increased demand for the offshoring firm's product translates into greater domestic employment at the firm level depends on two parameters, $\sigma$ and $\rho$. The higher the elasticity of substitution between varieties $(\sigma)$, the greater the increase in the demand for the good of a firm whose marginal cost declines. On the other hand, a high elasticity of substitution between inputs $(\rho)$ - so that domestic labor can be easily replaced by cheaper foreign labor - reduces the likelihood that the increase in demand for the firm's output translates into an increase in demand for domestic labor. In the end, after a decline in $\lambda$, the firm's domestic-labor demand increases through the productivity channel if and only if $\rho<\sigma$. In general, the productivity effect on employment is stronger the higher the $\sigma$ and the lower the $\rho$.

From (30) we know that the firm-level demand for domestic labor and $\hat{\varphi}$ have an inverse relationship: ceteris paribus, an increase in $\hat{\varphi}$ reduces the residual demand for each firm, which negatively affects firm-level profits (see equation (22)) and firm-level labor demand. We term the impact on a firm's labor demand resulting from a change in $\hat{\varphi}$ the "selection effect". In equation (39) the selection effect is given by $-(\sigma-1) \zeta_{\hat{\varphi}, \lambda}>0$ and thus, after a decline in $\lambda$ this effect is a source of job loss for all firms.

The intuition behind the selection effect of offshoring is similar to the domestic-market effect of final-good trade liberalization described by Melitz (2003). With offshoring firms setting lower 
prices due to the reduction in offshoring costs, market shares reallocate from non-offshoring to offshoring firms. The loss of market share for non-offshoring firms - and the consequent reduction in gross profits - implies that the productivity required to exactly meet the fixed cost of production is larger; that is, the cutoff productivity level below which firms exit, $\hat{\varphi}$, rises after a decline in $\lambda$. Therefore, non-offshoring firms contract and the least productive of them are forced to exit the market. Importantly, offshoring firms are also subject to the selection effect (as each of them competes with other offshoring firms who are also reducing their prices), and hence this effect also negatively affects their gross profits. Nevertheless, the positive productivity effect on offshoring firms' gross profits outweighs the negative selection effect and hence their gross profits increase after a decline in $\lambda .{ }^{12}$ However, whether the productivity effect of offshoring on firmlevel domestic employment dominates the selection effect depends crucially on the elasticity of substitution between inputs, $\rho$.

So far we have not discussed the labor-demand responses of firms whose offshoring status changes: initially non-offshoring firms that start to offshore, and vice versa. Recall that $\zeta_{\hat{\varphi}_{o}, \lambda}>0$ in Lemma 4 implies that $\hat{\varphi}_{o}$ declines after a decline in $\lambda$, which induces the firms with productivities between the new and the old $\hat{\varphi}_{o}$ to start offshoring. These firms face a discontinuity in their domestic-labor demand: their domestic-labor demand jumps from $L_{n}(\varphi)$ to $L_{o}(\varphi)$. From equation (30) note that when a firm changes from $L_{n}(\varphi)$ to $L_{o}(\varphi)$ due to a decline in $\lambda$, the same three effects described above are present and the only source of job creation is the productivity effect if $\rho<\sigma$.

The following proposition summarizes the implications of a change in the variable cost of offshoring for firm-level employment.

\section{Proposition 1. (Offshoring costs and firm-level domestic employment)}

A decline in the offshoring cost, $\lambda$, causes: (i) the death of the least productive non-offshoring firms, who then destroy all their jobs; (ii) job destruction at surviving non-offshoring firms; (iii) an ambiguous domestic labor response at existing offshoring firms if $\rho<\bar{\rho}$, where $\bar{\rho} \in(1, \sigma)$, but job destruction otherwise; (iv) an ambiguous domestic labor response at existing firms that begin to offshore if $\rho<\sigma$, but job destruction otherwise.

Part $(i)$ refers to the job destruction due to the death of firms between the old and new $\hat{\varphi}$ - these firms are wiped out due to the selection effect. Part (ii) refers to non-offshoring firms that survive after the decline in offshoring costs. Equation (39) shows that for these firms only the selection

\footnotetext{
${ }^{12}$ From (22), the gross profit function for offshoring firms is $\pi(\varphi)=\{\varphi /[c(\hat{\alpha}) \hat{\varphi}]\}^{\sigma-1} f$. From Lemma 4 we know that $c(\hat{\alpha})$ declines and $\hat{\varphi}$ rises after a decline in $\lambda$, but also $\zeta_{c(\hat{\alpha}), \lambda}>-\zeta_{\hat{\varphi}, \lambda}$. It follows that the effect on $c(\hat{\alpha})$ is stronger and hence, $c(\hat{\alpha}) \hat{\varphi}$ declines and $\pi(\varphi)$ increases.
} 
effect is present and hence, each of these firms destroys domestic jobs. Part (iii) refers to firms that offshore before and after the decline in offshoring costs. For these firms the impact of a change in $\lambda$ on domestic employment is given by the second line of (39) and they are subject to all the effects described above: the job-relocation effect, the productivity effect, and the selection effect. The productivity effect dominates the selection effect if and only if $\rho<\bar{\rho}$, where $\bar{\rho} \in(1, \sigma)$. If that is the case, and without further assumptions about the job-relocation effect, the net impact on firm-level employment is ambiguous. Given that $\bar{\rho}>1$, it follows that if there is complementarity between inputs $(\rho<1)$, the productivity effect always dominates the selection effect, making job creation by expansion more likely. In the case of $\rho \geq \bar{\rho}$, the productivity effect does not dominate the selection effect and hence, $\zeta_{L_{o}(\varphi), \lambda}>0$ and these firms experience job losses. Lastly, part (iv) refers to the labor-demand response of firms that begin to offshore after the decline in offshoring costs. For these firms, the job-relocation and selection effects cause job destruction, while the productivity effect causes job creation if and only if $\rho<\sigma$.

While our theoretical model has only one differentiated-good sector which can offshore inputs, it can be easily extended to a setting with multiple differentiated-good sectors. In this case, the results in Proposition 1 above suggest that the impact of offshoring on firm-level domestic employment in each industry will depend crucially on that industry's values of $\rho$ and $\sigma$. In particular, offshoring firms in industries with high $\sigma$ and low $\rho$ will experience strong productivity effects and can experience job gains upon offshoring. Regarding evidence on the heterogeneity of $\rho$ and firm-level employment effects, section 2 refers to Harrison and McMillan (2011), who provide empirical evidence showing that offshoring causes job creation in U.S. multinational firms that perform complementary tasks at home and abroad, and job destruction if tasks are substitutes.

Broda and Weinstein (2006) compute values of $\sigma$ for different U.S. industries at different levels of aggregation and find mean values of 17.3 (1972-1988 period) and 12.6 (1990-2001 period) for the most disaggregated categories, and mean values of 6.8 (1972-1988 period) and 4 (1990-2001 period) when aggregating industries at the SITC-3 level. Using data from West European countries, Goos, Manning, and Salomons (2014) provide an estimate of $\rho$ of about 0.9 (albeit at the aggregate level). Given the similarities between the U.S. and advanced European economies, it is likely that $\sigma>\rho$ for most industries and hence, the productivity effect on employment should be a source of job creation for offshoring firms in most cases. ${ }^{13}$ As well, ceteris paribus, the effect is stronger the higher the $\sigma$ for the industry.

\footnotetext{
${ }^{13}$ More generally, a value of $\rho$ below 1 for most industries (so that inputs are complementary and the productivity effect dominates the selection effect on domestic employment) and for most countries does not seem to be an unlikely scenario. For example, Jones (2011) shows that complementarity between intermediate goods - along with linkages between firms - can potentially explain a substantial part of the observed large cross-country income differences.
} 


\subsection{Industry-Level Employment Responses}

This section describes how a change in the offshoring cost, $\lambda$, affects the composition of firms and total domestic employment in the differentiated-good sector. The following proposition describes the changes in the mass of active firms, the mass of offshoring firms, and the mass of entrants when $\lambda$ declines.

\section{Proposition 2. (Offshoring costs and the mass of firms)}

After a decline in $\lambda$, the mass of offshoring firms, $N_{o}$, increases. However, there is an ambiguous response in the mass of entrants, $N_{E}$, the mass of active firms, $N$, and the mass of non-offshoring firms, $N_{n}$. The higher the value of $\eta$, the more likely it is that $N_{E}, N$, and $N_{n}$ increase after a decline in $\lambda$. In the special case with $\eta \rightarrow 1, N_{E}$ either declines or remains constant, and $N$ and $N_{n}$ decline.

In spite of the tougher competitive environment and the exit of some low productivity nonoffshoring firms, which cannot survive the competition from (the now more productive) offshoring firms, the effect on $N_{E}, N$, and $N_{n}$ is ambiguous due to the role played by the elasticity of demand for differentiated goods, $\eta$. If $\eta$ is high, a decline in $\lambda$ causes a large reallocation of expenditure towards differentiated goods, driving entry up. Even with a low $\eta$, the increase in the fraction of offshoring firms is large enough to lead to an increase in $N_{o}$.

Now, we can separate out the extensive- and intensive-margin components of net domestic employment changes in the differentiated-good sector. Recall that the extensive margin concerns changes in domestic employment due to births and deaths of firms, while the intensive margin refers to changes due to expansions and contractions of existing firms' domestic employment. Taking the derivative of equation (32) with respect to $\lambda$, we find that the effect of $\lambda$ on $L_{z}$ can be decomposed as

$$
\begin{aligned}
\frac{d L_{Z}}{d \lambda}= & \underbrace{\left[-L_{n}(\hat{\varphi}) g(\hat{\varphi}) \frac{d \hat{\varphi}}{d \lambda}\right] N_{E}+\frac{L_{Z}}{N_{E}} \frac{d N_{E}}{d \lambda}}_{\text {Net extensive margin }}+ \\
& \underbrace{\left[\left(L_{n}\left(\hat{\varphi}_{o}\right)-L_{o}\left(\hat{\varphi}_{o}\right)\right) g\left(\hat{\varphi}_{o}\right) \frac{d \hat{\varphi}_{o}}{d \lambda}+\int_{\hat{\varphi}}^{\hat{\varphi}_{o}} \frac{d L_{n}(\varphi)}{d \lambda} g(\varphi) d \varphi+\int_{\hat{\varphi}_{o}}^{\infty} \frac{d L_{o}(\varphi)}{d \lambda} g(\varphi) d \varphi\right] N_{E}}_{\text {Net intensive margin }} .
\end{aligned}
$$

The change in employment at the extensive margin occurs due to a change in the mass of producing firms, $N$. Recall from equation (27) that the mass of producing firms, $N$, equals $[1-G(\hat{\varphi})] N_{E}$. The two components of the net extensive margin in the above expression capture the employment effects due to changes in $\hat{\varphi}$ and $N_{E}$, which are the sources of change in $N$. The net intensive margin has three components: the first term accounts for the change in domestic employment of firms that 
change their offshoring status due to the effect of $\lambda$ on $\hat{\varphi}_{o}$; the second term accounts for the change in domestic employment of continuing non-offshoring firms; and the third term accounts for the change in domestic employment of continuing offshoring firms. The following proposition looks at each of the components of equation (40).

\section{Proposition 3. (Offshoring costs and net changes in sector- $Z$ 's employment)}

A decline in $\lambda$ has the following effects on domestic employment in the differentiated-good sector: (i) an ambiguous net effect at the extensive margin: job destruction is more likely when $\eta$ approaches 1 , and job creation is more likely when $\eta$ approaches $\sigma$; (ii) an ambiguous net effect at the intensive margin if $\rho<\sigma$ but job destruction otherwise; (iii) an ambiguous effect overall: net job creation is more likely for higher $\eta$ and lower $\rho$. If $\eta \rightarrow 1$ and $\rho \geq 1$, net job destruction is guaranteed.

Regarding part $(i)$, the net effect at the extensive margin is ambiguous - in spite of the destruction of domestic jobs due to the death of non-offshoring firms between the old and new $\hat{\varphi}$-because of the ambiguity in the response of $N_{E}$ discussed in Proposition 2. In the $\eta \rightarrow 1$ case, $N_{E}$ cannot increase after a reduction in $\lambda$ and hence there is job destruction at the extensive margin. Part (ii) concerns the signs and relative magnitudes of the three net-intensive-margin components in equation (40). Expanding the results in Proposition 1, we obtain that even though surviving nonoffshoring firms destroy domestic jobs after a decline in $\lambda$ (positive sign for the second term), the ambiguous domestic employment responses of new and existing offshoring firms - ambiguous signs for the first term (if $\rho<\sigma$ ) and the third term (if $\rho<\bar{\rho}$ ) - carry over to the overall net-intensivemargin effect. Adding the extensive and intensive margins, we obtain that the overall effect of a decline in offshoring costs is ambiguous in general; however, net job creation is more likely the higher the $\eta$ and the lower the $\rho$. In the special case with $\eta \rightarrow 1$ and $\rho \geq 1$, the job destruction at the extensive margin dominates any possible job creation at the intensive margin.

It is worth pointing out that although the elasticity of demand for differentiated goods, $\eta$, does not affect firm-level labor outcomes $\left(\hat{\alpha}, \hat{w}_{z}, \hat{\varphi}\right.$, and $\hat{\varphi}_{o}$ are independent of $\eta$, and hence, $L(\varphi)$ is also independent of $\eta$ ), it plays a crucial in determining the effect of $\lambda$ on $L_{z}$. In particular, $\eta$ affects industry-level employment by altering how the expenditure of households is allocated between homogeneous and differentiated goods.

As with our firm-level results in section 4.1, the results in Proposition 3 can be extended to a setting with multiple differentiated-good industries. In industries where there is a strong complementarity between domestic and offshored inputs (very low $\rho$ ) or the elasticity of demand for the industry's product is high (high $\eta$ ), offshoring may lead to an increase in employment. In other cases, however, a decrease in employment is the more likely outcome. As mentioned at the end of the previous section, existing estimates of $\sigma$ and $\rho$ make us confident that $\rho<\sigma$ for 
most industries (with $\rho<1$ being a strong possibility). We could not, however, find any reliable estimates of $\eta$ (industry-level elasticity of demand parameters).

\subsection{Offshoring Costs and the Economy-Wide Unemployment Rate}

From (35) we know that the economy-wide unemployment rate is $u=u_{H} \frac{\mathbb{L}_{H}}{\mathbb{L}}+u_{Z} \frac{\mathbb{L}_{Z}}{\mathbb{L}}$. Also, equations (9), (15), and (33) imply that sectoral unemployment rates, $u_{H}$ and $u_{Z}$, depend exclusively on search-friction parameters and, therefore, are not affected by offshoring costs. ${ }^{14}$ Thus, a change in offshoring costs affects the economy-wide unemployment rate only through its impact on the workforce composition. Given that $\mathbb{L}_{H}=\mathbb{L}-\mathbb{L}_{Z}$ and using equation (36), we can rewrite (35) as

$$
u=u_{H}+\left(\frac{u_{Z}-u_{H}}{1-u_{Z}}\right) \frac{L_{Z}}{\mathbb{L}} .
$$

It follows that

$$
\frac{d u}{d \lambda}=\left[\frac{u_{Z}-u_{H}}{\mathbb{L}\left(1-u_{Z}\right)}\right] \frac{d L_{Z}}{d \lambda}
$$

and hence $\frac{d u}{d \lambda}$ and $\frac{d L_{Z}}{d \lambda}$ have the same sign if $u_{Z}>u_{H}$, and they have opposite signs if $u_{Z}<u_{H}$.

Suppose the search parameters are such that $u_{Z}<u_{H}$. In this case, if $\eta$ is sufficiently high and $\rho$ is sufficiently low so that a decline in offshoring costs increases the share of the workforce affiliated with sector $Z$, then the economy-wide unemployment rate declines because workers are moving from the high-unemployment sector $(H)$ to the low-unemployment sector $(Z)$. In general, however, we know from Proposition 3 that the impact of offshoring on $L_{z}$ is ambiguous and therefore, from (42) it follows that the same must be true for the economy-wide unemployment rate. Nevertheless, we can write the following corollary to Proposition 3.

Corollary 1. If search frictions are higher in the differentiated-good sector so that $u_{Z}>u_{H}, a$ decline in offshoring costs is likely to reduce unemployment when $\rho$ is high and $\eta$ is low. If $u_{H}>u_{Z}$, a decline in offshoring costs is likely to reduce unemployment when $\rho$ is low and $\eta$ is high.

\subsection{Offshoring and Welfare}

While the focus of our paper is on the employment effects of offshoring, we can also derive welfare implications. Note from equation (3) that the welfare of the representative household is inversely related to the price index, $P$, and positively related to the spending, E. From (7) and (38), it follows that $E$ does not change in response to a change in $\lambda$ or $f_{o}$. Since $P$ declines in response to either a decline in $\lambda$ or $f_{o}$ ( $\hat{\varphi}$ increases when $\lambda$ or $f_{o}$ decline, and from (21) we know that $P$ and $\hat{\varphi}$ have an inverse relationship) we obtain the following result.

\footnotetext{
${ }^{14}$ This result is analogous to the result of independence between final-good trade costs and sectoral unemployment rates in Helpman and Itskhoki (2010) and is a consequence of modeling vacancy cost in terms of the homogeneous good. In section 6.1 below we discuss the consequences of alternative specifications of the vacancy cost.
} 


\section{Proposition 4. (Offshoring and Welfare)}

A decrease in the cost of offshoring (fixed or variable) leads to an increase in welfare.

Intuitively, offshoring always leads to productivity improvements for the economy, which shows up in a lower price index for differentiated goods and consequently in an increase in welfare. The result above is notable because we have labor market frictions in the model and it is possible for a decrease in the cost of offshoring to lead to an increase in unemployment. However, our assumption of a representative household implies everyone gains from offshoring.

As mentioned in the Introduction, some caveats about this result are in order. First, in reality labor income risk cannot be diversified away, which means that unemployed workers have lower welfare than employed workers; an increase in unemployment induced by offshoring creates some losers - the newly unemployed. Second, if workers are highly risk averse, any increase in unemployment caused by offshoring can inflict large losses on workers by increasing the labor market risk, which then must be weighed against the efficiency gains inherent in the proposition above. Even if workers are risk neutral, some of them could still lose from offshoring if there are mobility costs as was shown in Mitra and Ranjan (2010). Since the focus of this paper is on identifying the channels through which offshoring affects unemployment, we abstract from these broader welfare issues by relying on the simplifying assumption of a risk neutral representative household.

\section{$5 \quad$ Search Frictions and Jobs}

The impact of a change in search frictions can be easily studied in our model. The key equation for this analysis is equation (16), which we recall is $\hat{w}_{Z} \equiv \frac{m_{H}}{m_{Z}}\left(\frac{\gamma_{Z}}{\gamma_{H}}\right)^{1-\beta}$. That is, search-friction parameters affect jobs by altering the cost of hiring a unit of domestic labor in the differentiatedgood sector, $\hat{w}_{z}$. Given that $\beta \in(0,1)$, note that $\hat{w}_{z}$ is increasing in $\gamma_{z}$ and $m_{H}$, and decreasing in $\gamma_{H}$ and $m_{Z}$. There is a reduction in search frictions in sector $i$ when either $\gamma_{i}$ declines or $m_{i}$ increases. Therefore, a reduction in search frictions in the differentiated-good sector lowers $\hat{w}_{Z}$, and a reduction in search frictions in the homogeneous-good sector increases $\hat{w}_{z}$. While a reduction in search frictions in the differentiated goods sector directly reduces the cost of hiring labor there, a reduction in search frictions in the homogeneous-good sector raises the outside option of workers in the differentiated-good sector making it more costly for firms to hire domestic labor.

The following lemma contains results that will allow us to understand the effects of changes in search frictions on offshoring decisions and jobs.

Lemma 5. $\zeta_{\hat{\alpha}, \hat{w}_{Z}}>0, \zeta_{c(\hat{\alpha}), \hat{w}_{Z}}<0, \zeta_{\hat{\varphi}_{,} \hat{w}_{Z}}>0, \zeta_{\hat{\varphi}_{o}, \hat{w}_{Z}}<0$. 
By lowering $\hat{w}_{z}$, a decrease in search frictions in the differentiated-good sector makes offshoring less attractive, which in turn reduces the fraction of offshored inputs, $\zeta_{\hat{\alpha}, \hat{w}_{Z}}>0$, and erodes the relative cost advantage of offshoring firms, $\zeta_{c(\hat{\alpha}), \hat{w}_{Z}}<0$. The proportional decrease in the marginal cost of offshoring firms is less than that of non-offshoring firms, which leads to easier survival conditions for non-offshoring firms: $\zeta_{\hat{\varphi}, \hat{w}_{Z}}>0$. As well, the reduced attractiveness of offshoring leads to an increase in the offshoring productivity cutoff: $\zeta_{\hat{\varphi}_{o}, \hat{w}_{Z}}<0$.

From (30) we obtain that the elasticity of firm-level domestic employment, $L_{s}(\varphi)$, with respect to $\hat{w}_{Z}$ is given by

$$
\zeta_{L_{s}(\varphi), \hat{w}_{Z}}= \begin{cases}-(\sigma-1) \zeta_{\hat{\varphi}^{,} \hat{w}_{Z}}-1 & \text { if } s=n \\ -\frac{\hat{\alpha}}{1-\hat{\alpha}} \zeta_{\hat{\alpha}, \hat{w}_{Z}}-(\sigma-\rho) \zeta_{c(\hat{\alpha}), \hat{w}_{Z}}-(\sigma-1) \zeta_{\hat{\varphi}_{,} \hat{w}_{Z}}-1 & \text { if } s=o .\end{cases}
$$

After a decline in $\hat{w}_{z}$, employment at non-offshoring firms increases not only because of the selection effect, $-(\sigma-1) \zeta_{\hat{\varphi}, \hat{w}_{Z}}<0$, but also because of the direct effect of a decrease in their marginal cost and the consequent increase in demand (accounted for by -1 ). For offshoring firms we again have the three effects - job relocation, selection, and productivity - in addition to the direct effect of a lower marginal cost. As before, the productivity effect moves in the opposite direction to the other effects if $\rho<\sigma$, and in the same direction otherwise. Also $\hat{\varphi}_{o}$ increases, so there are firms that stop offshoring - for these firms we observe the four effects directly from (30).

The proposition below summarizes the results discussed above as well as the implications of changes in search frictions on the overall employment in the differentiated goods sector.

\section{Proposition 5. (Search frictions and differentiated-good-sector employment)}

$A$ decline in search frictions in sector $Z$-or an increase in search frictions in sector $H-$ lowers $\hat{w}_{Z}$, which affects sector-Z's domestic employment and the mass of firms as follows: (i) job creation due to the birth of low productivity non-offshoring firms; (ii) job creation at continuing non-offshoring firms; (iii) an ambiguous domestic labor response at continuing offshoring firms if $\rho<\tilde{\rho}$, where $\tilde{\rho}<\sigma-1$, but job creation otherwise; (iv) an ambiguous response at firms that switch from offshoring to non-offshoring if $\rho<\sigma$, but job creation otherwise; (v) increases in $N_{E}, N$, and $N_{n}$, but an ambiguous response in $N_{o}$; (vi) net job creation at the extensive margin, and an ambiguous response at the intensive margin and overall if $\rho<\sigma$, but net job creation otherwise. Finally, higher $\eta$ and $\rho$ promote stronger job creation when $\hat{w}_{z}$ declines.

Regarding the economy-wide unemployment rate, one key difference from the case of a change in offshoring costs is that a change in search frictions affects the economy-wide unemployment rate not only through its impact on the workforce composition, but also through its effect on sectoral unemployment rates. For example, a decline in $\gamma_{z}$ affects $L_{z}$ via a decrease in $\hat{w}_{z}$, but also causes 
a decline in $u_{z}$ - see (15) and (33). From (41) note that, as opposed to the simpler response for a change in $\lambda$ in (42), the response of $u$ to a change in $\gamma_{Z}$ is given by

$$
\frac{d u}{d \gamma_{Z}}=\frac{1}{\left(1-u_{Z}\right) \mathbb{L}}\left[\left(u_{Z}-u_{H}\right) \frac{d L_{Z}}{d \hat{w}_{Z}} \frac{d \hat{w}_{Z}}{d \gamma_{Z}}+\left(\frac{1-u_{H}}{1-u_{Z}}\right) \frac{d u_{Z}}{d \gamma_{Z}} L_{Z}\right]
$$

An interesting possibility is the following perverse result. Even though $u_{z}$ is smaller after a decline in $\gamma_{Z}$, an increase in the number of workers searching for a job in that sector may raise the economywide unemployment rate if $u_{Z}$ was higher than $u_{H}$ to begin with.

From Proposition 5 we know that the effects of an increase in sector- $H$ 's search frictions on differentiated-good-sector employment are similar to those of a decline in sector- $Z$ 's frictions. However, the implications for the economy-wide unemployment rate could be quite different. Consider, for example, a change in $\gamma_{H}$. Note from (9) and (15) that $\gamma_{H}$ affects labor market tightness in both sectors, $\theta_{H}$ and $\theta_{Z}$, and therefore, it affects both sectoral unemployment rates, $u_{H}$ and $u_{Z}$. Hence, a change in $\gamma_{H}$ affects $u$ in (41) through its impact on $u_{H}, u_{Z}$, and $L_{Z}$.

Therefore, changes in search frictions have both direct and indirect effects on labor markets. The indirect effects work through the interaction of search frictions with offshoring. Interestingly, the lowering of search frictions does not necessarily guarantee a lower economy-wide unemployment rate.

\section{Discussion and Extensions}

This section discusses some robustness issues related to the modeling of the vacancy cost, describes an extension of our model to account for trade in final goods, and discusses our assumption of domestic and foreign wages that are independent of offshoring costs.

\subsection{Alternative Ways of Modeling Vacancy Cost}

In our framework, the sectoral unemployment rates are independent of offshoring costs, which is a consequence of modeling the vacancy cost in terms of the homogeneous good (see footnote 14 in section 4.3). It is this assumption which makes the wages in both sectors independent of offshoring, thereby making the outside option of workers in the offshoring sector insensitive to offshoring. While this simplifies the analysis considerably, allowing us to focus on the employment effects of offshoring, it is clearly a limitation of the model. This section discusses alternative specifications of the vacancy cost that allow offshoring to affect wages and sectoral unemployment rates.

One could model the vacancy cost in terms of forgone sectoral output. That is, the vacancy cost in sector $H$ is in terms of the homogeneous good and in sector $Z$ is in terms of the composite differentiated good. In this case, the wage and unemployment rate in the homogeneous sector 
are exactly the same as in our current set up, which again make the outside option of workers independent of offshoring. However, the wage and unemployment rate in the differentiated-good sector respond to offshoring. To see this clearly, note that if the vacancy cost in sector $Z$ is $\gamma_{Z}$ units of the composite differentiated good, then the vacancy cost in terms of the numéraire good $H$ is $P \gamma_{Z}$. Replacing $\gamma_{Z}$ by $P \gamma_{Z}$ in equations (14) and (15), it can be verified that a decrease in $P$ reduces $w_{Z}$ and raises $\theta_{Z}$. That is, both the wage and the unemployment rate in sector $Z$ decline as $P$ decreases because of a reduction in the offshoring cost. Intuitively, a reduction in the offshoring cost also reduces the cost of creating a vacancy in sector $Z$, leading to lower unemployment. Free mobility of workers implies that wages must fall in sector $Z$ to keep the workers indifferent between the two sectors. The impact on the economy-wide unemployment will depend on whether $L_{z}$ increases or decreases.

Vacancy costs could also be modeled in terms of the composite differentiated good, $Z$, for both sectors. The outcome under this assumption can be inferred from equations (8), (9), (14) and (15) after replacing $\gamma_{H}$ by $P \gamma_{H}$ and $\gamma_{Z}$ by $P \gamma_{Z}$. In this case, a reduction in the offshoring cost leads to a decrease in $P$ and an increase in $\theta_{H}$, giving rise to lower unemployment in the homogeneous sector. Since $w_{H}$ (which equals $\beta$ ) is independent of the vacancy cost, the expected income $\underline{w}$ increases. A higher $\underline{w}$ increases the outside option of workers in the differentiated-good sector, which shows up in a lower unemployment rate in that sector as well. The differentiated-good sector wage, $w_{z}$, is unchanged because it depends on the ratio of the vacancy costs in the two sectors, which remains unchanged. The economy-wide unemployment rate again depends on what happens to $L_{z}$.

Lastly, vacancy costs could be modeled in terms of a composite of the two consumption goods ( $H$ and $Z$ ) as in Mitra and Ranjan (2010). In our notation, the vacancy cost in sector- $i$ would be $f(P) \gamma_{i}$, where $f(P)$ is the price of the two-sector composite good and $f^{\prime}(P)>0$. Again, since offshoring lowers the price of good $Z$, it lowers the vacancy cost in both sectors. Therefore, the results are similar to those mentioned in the previous paragraph.

Therefore, different ways of modeling the vacancy cost lead to different results on sectoral unemployment rates and wages. However, in all cases the economy-wide unemployment rate crucially depends on what happens to $L_{Z}$.

The result on welfare gains from offshoring is a more robust prediction, which has to do with the similarity of offshoring to a technological improvement combined with a representative agent framework. From the discussion above, note that the expected labor income, $\underline{w}$, either increases or remains unchanged after a reduction in offshoring costs. Since the price index of the differentiated goods, $P$, decreases upon offshoring, welfare gains occur irrespective of the way we model the vacancy cost. 


\subsection{Trade in Final Goods}

To highlight the effects of offshoring costs on domestic jobs due to input trade, the previous model abstracts from trade in final goods. However, it is possible that better offshoring opportunities - as reflected in lower offshoring costs - also expand final-good trade: when a firm begins to offshore, it becomes more competitive in both domestic and foreign final-good markets. Hence, offshoring costs affect jobs through their impact on trade in final goods as well. In the working paper version of this manuscript (Groizard, Ranjan, and Rodriguez-Lopez, 2013) we account for these employment effects by developing an explicit North-South extension of the model with trade in both intermediate inputs and final goods. ${ }^{15}$

In a setting where Northern firms offshore input production to the South, it is shown that a decrease in the cost of offshoring makes the Northern firms more productive relative to the Southern firms in both markets. As a consequence, the numbers of entrants and exporting firms increase in the North, which leads to net job creation at the extensive margin-recall that in the absence of exporting opportunities, there is no guarantee of net job creation at the extensive margin. At the intensive margin, in addition to the job relocation, productivity, and selection effects arising from Northern firms' sales to their domestic market, these effects arise for Northern firms' export sales as well. While the job-relocation and productivity effects for export sales are similar to those for domestic sales, the selection effect in the export market is different. In particular, while the selection effect relevant for domestic sales leads to job destruction, the selection effect relevant for exports leads to job creation. This offshoring-induced job creation due to exporting possibilities increases the likelihood that the overall effect of offshoring on differentiated-good sector employment is positive.

The impact on the economy-wide unemployment rate depends again on the composition of the workforce and the extent of search frictions in the two sectors. The extended model also allows us to do comparative statics with respect to the trading cost of differentiated goods. One notable result compared to the case of a change in the offshoring cost is the absence of job-relocation and productivity effects. In fact, we show that a decline in the offshoring cost and a decline in the cost of trading differentiated goods can have opposite effects on the economy-wide unemployment rate. Nevertheless, the two trading costs interact in significant ways: the impact of a decrease in the cost of trading differentiated goods on job flows is larger the smaller the offshoring cost and vice versa.

\footnotetext{
${ }^{15}$ An important stylized fact in micro-level data is that importing of inputs and exporting go hand in hand in many firms. For example, Bernard, Jensen, and Schott (2009) document that $42 \%$ of the U.S. civilian employment at private firms was in trading firms, while $30 \%$ of the employment was at the firms that do both export and import. As well, Bernard, Jensen, Redding, and Schott (2007) show that $79 \%$ of firms in the U.S. that import also export.
} 


\subsection{Fixed Wages}

In our model, domestic nominal wages in both sectors are pinned down by search-friction parameters and do not respond to changes in offshoring costs. In addition, the foreign wage is exogenous. These simplifying assumptions are made to keep the focus of the paper on the employment effects of offshoring. Note, however, that even though the nominal wage is constant, the real wage is endogenous. In fact, the real cost of labor in the differentiated-good sector is $\frac{\hat{w}_{Z}}{P}$, which increases due to offshoring. One can think of this increase in the real wage as being the driving force behind the selection effect, which causes the exit of low-productivity firms, as was the case in Melitz (2003).

Our assumption of an exogenous foreign wage (which we also keep in the North-South extension in the working paper version) is mostly harmless if there are large and persistent wage differences between the source and destination countries. This story is consistent with the offshoring relationship between the U.S. firms and the Mexican maquiladoras or the Chinese processing firms (China and Mexico are two of the three main trading partners of the U.S.): the U.S. Bureau of Labor Statistics (BLS) reports that hourly labor costs in manufacturing in Mexico as percentage of hourly labor costs in U.S. manufacturing were 15\% in 1997 and $18 \%$ in 2012, while for China these numbers were $2 \%$ in 2002 and $5 \%$ in $2009 .{ }^{16}$ Importantly, even if we endogenize the foreign wage - so that an increase in offshoring increases the demand for foreign labor and drives up the foreign wage - all the channels identified in this paper will still be present leaving the qualitative results unchanged. The endogenous response of the foreign wage $w^{*}$ to changes in $\lambda$ will make the employment responses quantitatively smaller.

\section{Concluding Remarks}

We construct a two-sector theoretical model with labor market frictions to study the impact of offshoring on jobs at the firm and industry levels and on the economy-wide unemployment rate. We identify three channels through which a reduction in the cost of offshoring affects intrafirm and intrasectoral reallocation in the differentiated-good sector: a job-relocation effect, a productivity effect, and a selection effect. After a decline in offshoring costs, the job-relocation and selection effects generate job losses, while the productivity effect can generate job expansions for offshoring firms. The key parameters determining the impact of offshoring on reallocation of jobs at various margins as well as on the economy-wide unemployment are the elasticities of substitution in production and consumption for differentiated goods, and the elasticity of demand for the differentiated-good sector as a whole.

\footnotetext{
${ }^{16}$ In the BLS International Labor Comparisons website, see Table 1 in http://www.bls.gov/fls/ichcc.pdf for Mexico and see http://www.bls.gov/ilc/china.htm for China.
} 
As mentioned in section 2, our model of offshoring bears similarity to recent models of routinetask replacing technical change. Using data from European countries, Goos, Manning, and Salomons (2014) attempt to disentangle the effects of offshoring and routine-biased technical change (RBTC) by constructing measures of offshorability and routineness for different occupations. ${ }^{17} \mathrm{~A}$ natural empirical application of our model with firm heterogeneity would be to disentangle the effects of offshoring and RBTC on firm- and industry-level employment by exploiting variations in computerization and offshoring costs over time and across industries.

\section{References}

Amiti, M., And J. Konings (2007): "Trade Liberalization, Intermediate Inputs, and Productivity: Evidence from Indonesia," American Economic Review, 97(5), 1611-1638.

Amiti, M., And S.-J. Wei (2005): "Fear of Service Outsourcing: Is It Justified?," Economic Policy, 20(42), 308-347.

(2009): "Service Offshoring and Productivity: Evidence from the US," The World Economy, 32(2), 203-220.

Antràs, P., And E. Helpman (2004): "Global Sourcing," Journal of Political Economy, 112(3), $552-580$.

Autor, D. H. (2013): "The "Task Approach" to Labor Markets: An Overview," Journal for Labour Market Research, 46(3), 185-199.

Autor, D. H., And D. Dorn (2013): "The Growth of Low-Skill Service Jobs and the Polarization of the US Labor Market," American Economic Review, 103(5), 1553-1597.

Autor, D. H., F. Levy, and R. J. Murnane (2003): "The Skill Content Of Recent Technological Change: An Empirical Exploration," Quarterly Journal of Economics, 118(4), 1279-1333.

Bernard, A. B., J. B. Jensen, S. J. Redding, and P. K. Schott (2007): "Firms in International Trade," Journal of Economic Perspectives, 21(3), 105-130.

Bernard, A. B., J. B. Jensen, and P. K. Schott (2009): "Importers, Exporters and Multinationals: A Portrait of Firms in the U.S. that Trade Goods," in Producer Dynamics: New Evidence from Micro Data, pp. 513-552. University of Chicago Press.

Bernard, A. B., S. J. Redding, and P. K. Schott (2007): "Comparative Advantage and Heterogeneous Firms," Review of Economic Studies, 74(1), 31-66.

Broda, C., And D. E. Weinstein (2006): "Globalization and the Gains from Variety," The Quarterly Journal of Economics, 121(2), 541-585.

\footnotetext{
${ }^{17}$ Although they attribute most of the effect on employment to RBTC, they acknowledge that correct identification is difficult due to the strong correlation between their offshorability and routineness measures.
} 
Davidson, C., and S. J. Matusz (2004): International Trade and Labor Markets: Theory, Evidence, and Policy Implications. W. E. Upjohn Institute.

Davidson, C., S. J. Matusz, and A. Shevchenko (2008): "Outsourcing Peter To Pay Paul: High-Skill Expectations And Low-Skill Wages With Imperfect Labor Markets," Macroeconomic Dynamics, 12(4), 463-479.

Egger, H., U. Kreickemeier, and J. Wrona (2013): "Offshoring Domestic Jobs," CESifo Working Paper Series 4083, CESifo Group Munich.

Felbermayr, G., J. Prat, and H.-J. Schmerer (2011): "Globalization and labor market outcomes: Wage bargaining, search frictions, and firm heterogeneity," Journal of Economic Theory, 146(1), 39-73.

Felbermayr, G. J., G. Impullitti, and J. Prat (2014): "Firm Dynamics and Residual Inequality in Open Economies," CESifo Working Paper Series 4666, CESifo Group Munich.

Goldberg, P. K., A. K. Khandelwal, N. Pavcnik, and P. Topalova (2010): "Imported Intermediate Inputs and Domestic Product Growth: Evidence from India," Quarterly Journal of Economics, 125(4), 1727-1767.

Goos, M., A. Manning, and A. Salomons (2014): "Explaining Job Polarization: RoutineBiased Technological Change and Offshoring," American Economic Review, 104(8), 2509-2526.

Gopinath, G., and B. Neiman (2013): "Trade Adjustment and Productivity During Large Crises," American Economic Review, forthcoming.

Görg, H. (2011): "Globalization, Offshoring and Jobs," in Making Globalization Socially Sustainable, ed. by M. Bacchetta, and M. Jansen. World Trade Organization.

Görg, H., ANd A. HAnley (2005): "Labour Demand Effects of International Outsourcing: Evidence from Plant-Level Data," International Review of Economics \& Finance, 14(3), 365-376.

Groizard, J. L., P. Ranjan, and A. Rodriguez-Lopez (2013): "Offshoring, Exporting, and Jobs," CESifo Working Paper Series 4550, CESifo Group Munich.

(2014): "Trade Costs and Job Flows: Evidence from Establishment-Level Data," Economic Inquiry, forthcoming.

Grossman, G. M., and E. Rossi-Hansberg (2008): "Trading Tasks: A Simple Theory of Offshoring," American Economic Review, 98(5), 1978-97.

Harrison, A., and M. McMillan (2011): "Offshoring Jobs? Multinationals and U.S. Manufacturing Employment," Review of Economics and Statistics, 93(3), 857-875.

Helpman, E., and O. Itskhoki (2010): "Labour Market Rigidities, Trade and Unemployment," Review of Economic Studies, 77(3), 1100-1137.

Hijzen, A., And P. Swaim (2007): "Does Offshoring Reduce Industry Employment?," National Institute Economic Review, 201(1), 86-96.

IbSen, R., F. Warzynski, and N. Westergard-Nielsen (2010): "Employment Growth and International Trade: A Small Open Economy Perspective," Aarhus School of Business, Department of Economics. 
Jones, C. I. (2011): "Intermediate Goods and Weak Links in the Theory of Economic Development," American Economic Journal: Macroeconomics, 3(2), 1-28.

Melitz, M. J. (2003): "The Impact of Trade on Intra-Industry Reallocations and Aggregate Industry Productivity," Econometrica, 71(6), 1695-1725.

Melitz, M. J., And S. J. Redding (2013): "Firm Heterogeneity and Aggregate Welfare," NBER Working Papers 18919, National Bureau of Economic Research, Inc.

Mitra, D., And P. Ranjan (2010): "Offshoring and Unemployment: The Role of Search Frictions Labor Mobility," Journal of International Economics, 81(2), 219-229.

Moen, E. R. (1997): "Competitive Search Equilibrium," Journal of Political Economy, 105(2), $385-411$.

Moore, M. P., And P. Ranjan (2005): "Globalisation vs Skill-Biased Technological Change: Implications for Unemployment and Wage Inequality," Economic Journal, 115(503), 391-422.

Ranjan, P. (2013): "Offshoring, Unemployment, and Wages: The Role of Labor Market Institutions," Journal of International Economics, 89(1), 172-186.

Shimer, R. (1996): "Contracts in a Frictional Labor Market," manuscript, Massachusetts Institute of Technology.

Stole, L. A., And J. Zwiebel (1996): "Intra-Firm Bargaining under Non-Binding Contracts," Review of Economic Studies, 63(3), 375-410.

Topalova, P., and A. Khandelwal (2011): "Trade Liberalization and Firm Productivity: The Case of India," Review of Economics and Statistics, 93(3), 995-1009.

Wagner, J. (2011): "Offshoring and Firm Performance: Self-Selection, Effects on Performance, or Both?," Review of World Economics, 147(2), 217-247.

Wright, G. C. (2014): "Revisiting the Employment Impact of Offshoring," European Economic Review, 66, 63-83. 